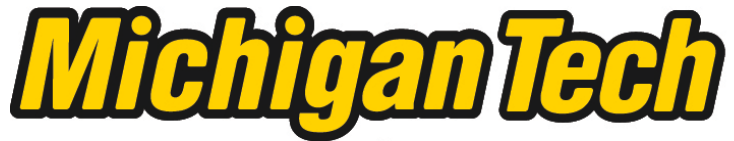 \\ Michigan Technological University Create the Future Digital Commons @ Michigan Tech
}

2014

\section{SLOPE STABILITY ANALYSIS OF MOUNT MEAGER, SOUTH- WESTERN BRITISH COLUMBIA, CANADA}

Rachel M. Hetherington

Michigan Technological University

Follow this and additional works at: https://digitalcommons.mtu.edu/etds

Part of the Geology Commons, and the Geomorphology Commons Copyright 2014 Rachel M. Hetherington

\section{Recommended Citation}

Hetherington, Rachel M., "SLOPE STABILITY ANALYSIS OF MOUNT MEAGER, SOUTH-WESTERN BRITISH COLUMBIA, CANADA", Master's Thesis, Michigan Technological University, 2014.

https://doi.org/10.37099/mtu.dc.etds/764

Follow this and additional works at: https://digitalcommons.mtu.edu/etds

Part of the Geology Commons, and the Geomorphology Commons 
SLOPE STABILITY ANALYSIS OF MOUNT MEAGER, SOUTH-WESTERN BRITISH COLUMBIA, CANADA

\author{
By \\ Rachel M. Hetherington
}

\begin{abstract}
A THESIS
Submitted in partial fulfillment of the requirements for the degree of MASTER OF SCIENCE

In Geology
\end{abstract}

MICHIGAN TECHNOLOGICAL UNIVERSITY

2014

(C) 2014 Rachel M. Hetherington 
This thesis has been approved in partial fulfillment of the requirements for the Degree of MASTER OF SCIENCE in Geology.

Department of Geological and Mining Engineering and Sciences

Thesis Co-Advisor: Dr. Thomas Oommen

Thesis Co-Advisor: $\quad$ Dr. Benjamin Van Wyk de Vries

Committee Member: Dr. Greg Waite

Department Chair: Dr. John Gierke 


\section{Contents}

i. $\quad$ Abstract...............................................................................

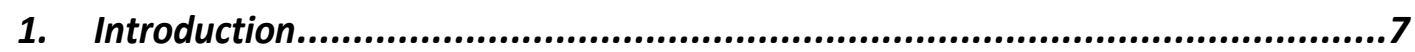

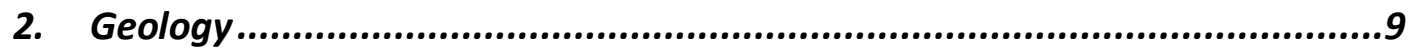

3. Landslide History.........................................................................11

3.1. Prehistoric and Historic Activity .................................................... 11

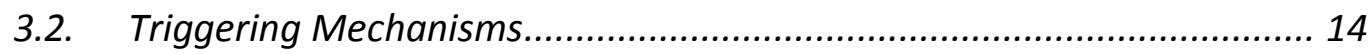

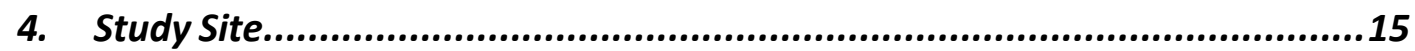

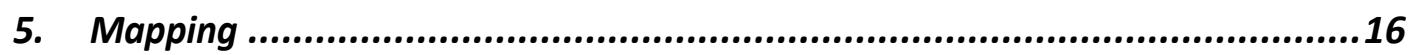

5.1. Features Indicating Movement ......................................................... 17

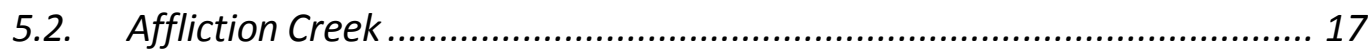

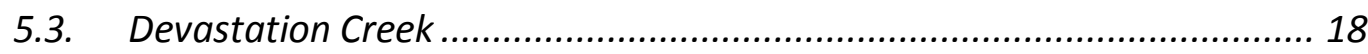

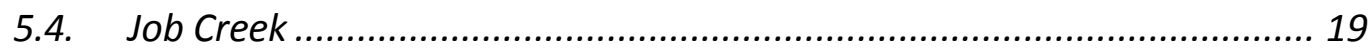

5.5 The Flanks of the Devastator and Pylon ............................................ 20

5.6 Capricorn Creek ......................................................................... 21

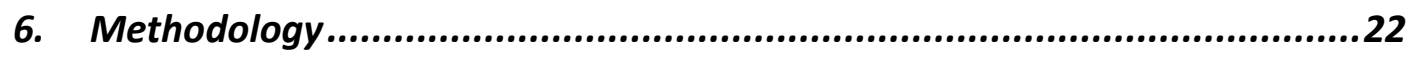

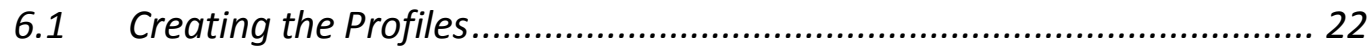

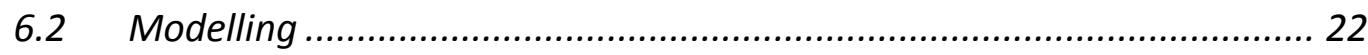

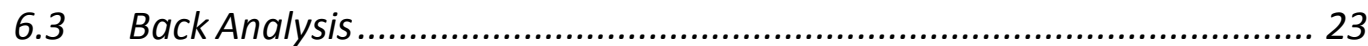

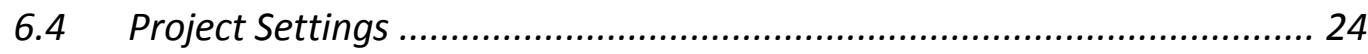

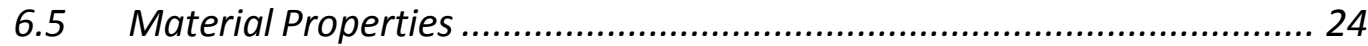

6.6 Water Table................................................................................ 25

$6.7 \quad$ Hydraulic Properties ..................................................................... 25

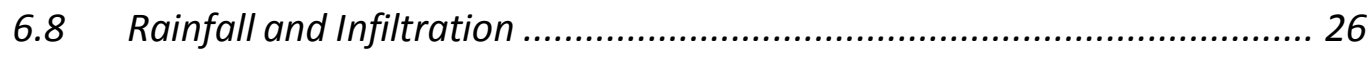

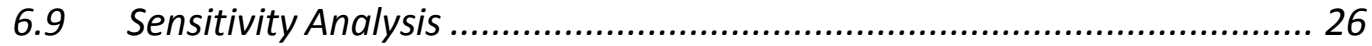

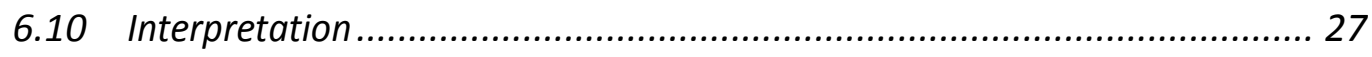

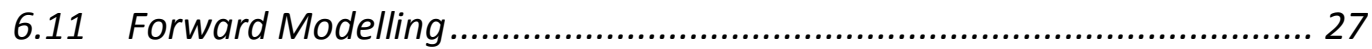




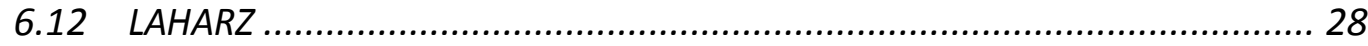

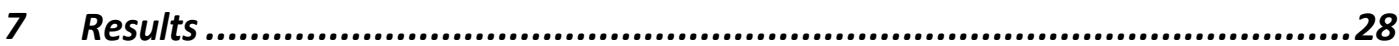

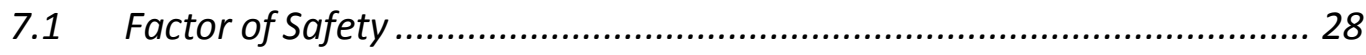

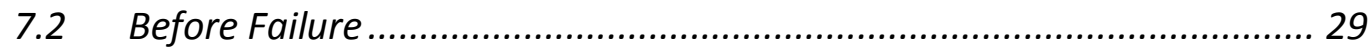

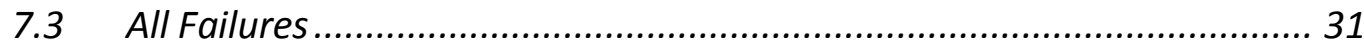

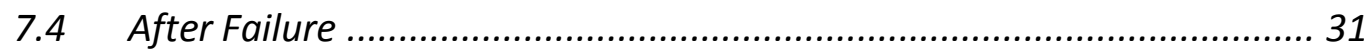

7.5 South West - North East Profile ............................................................. 35

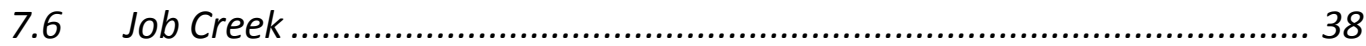

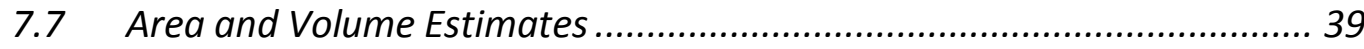

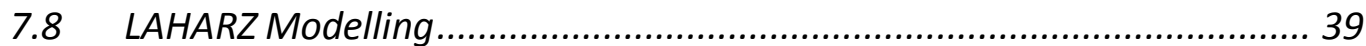

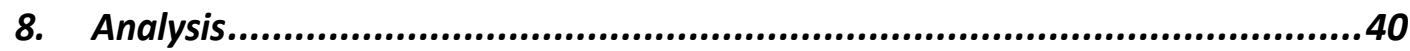

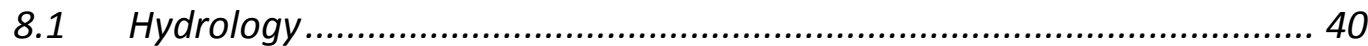

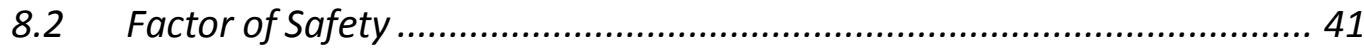

8.3 South West - North East Profile .......................................................... 41

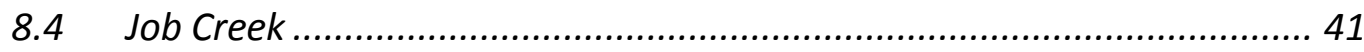

8.5 Modelling Extremes........................................................................ 42

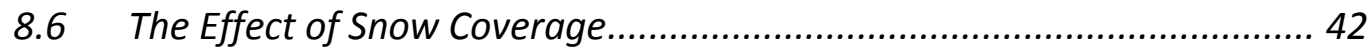

8.7 Model Assumptions and Validity ....................................................... 42

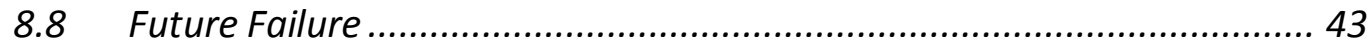

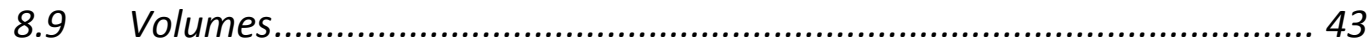

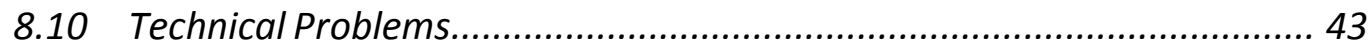

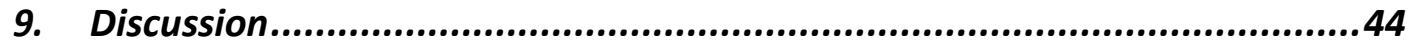

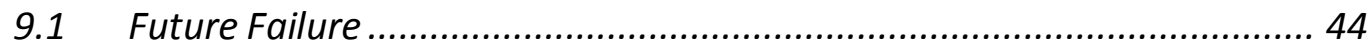

9.2 Climate Change ................................................................................ 45

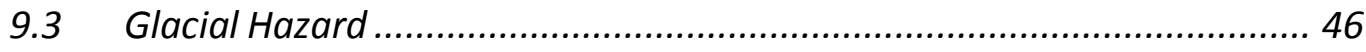

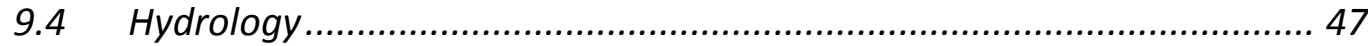

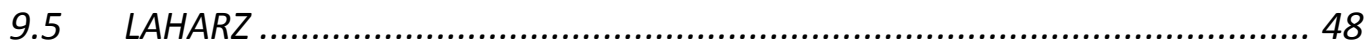

9.6 Overview of Similar Failures in British Columbia ….................................. 50 


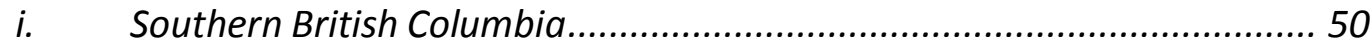

ii. Northern British Columbia................................................................. 50

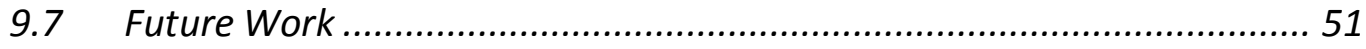

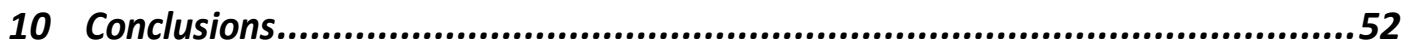

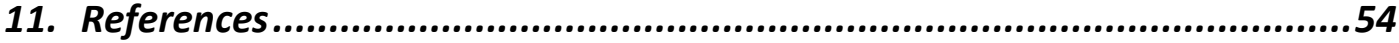

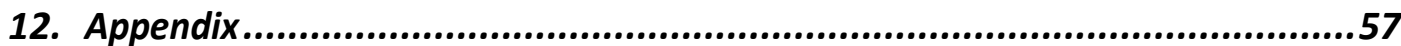

12.1 License and Copyright Agreement for Guthrie et al., (2012). Figures 1, 5, 6,

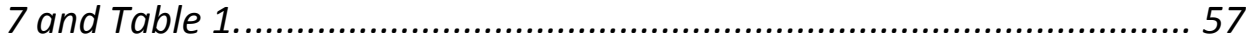

12.2 License for Bovis \& Jakob (2000). Figures 3 and 19............................ 60

12.3 License for Friele \& Clague (2004). Figure 18..................................... 61

12.4 License for Hewitt et al., (2008). Figure 11....................................... 62

12.5 License for Holm et al., (2004). Figure 12.......................................... 63

12.6 Copyright Agreement for Read (1990). Figures 4 and 8........................ 64

12.7 License for Simpson et al., (2006). Figures 2 and 9.............................. 65

12.8. License for Google Earth. Figures 10, 13, 14, 15, 16 and 17...................66

12.9 License agreement from USGS. Figure 30........................................ 68 


\section{i. Abstract}

The Mount Meager Volcanic Complex (MMVC) in south-western British Columbia is a potentially active, hydrothermally altered massif comprising a series of steep, glaciated peaks. Climatic conditions and glacial retreat has led to the further weathering, exposure and de-buttressing of steep slopes composed of weak, unconsolidated material. This has resulted in an increased frequency of landslide events over the past few decades, many of which have dammed the rivers bordering the Complex. The breach of these debris dams presents a risk of flooding to the downstream communities. Preliminary mapping showed there are numerous sites around the Complex where future failure could occur. Some of these areas are currently undergoing progressive slope movement and display features to support this such as anti-scarps and tension cracks. The effect of water infiltration on stability was modelled using the Rocscience program Slide 6.0. The main site of focus was Mount Meager in the south- east of the Complex where the most recent landslide took place. Two profiles through Mount Meager were analysed along with one other location in the northern section of the MMVC, where instability had been detected. The lowest Factor of Safety (FOS) for each profile was displayed and an estimate of the volume which could be generated was deduced. A hazard map showing the inundation zones for various volumes of debris flows was created from simulations using LAHARZ. Results showed the massif is unstable, even before infiltration. Varying the amount of infiltration appears to have no significant impact on the FOS annually implying that small changes of any kind could also trigger failure. Further modelling could be done to assess the impact of infiltration over shorter time scales. The Slide models show the volume of material that could be delivered to the Lillooet River Valley to be of the order of $10^{9} \mathrm{~m}^{3}$ which, based on the LAHARZ simulations, would completely inundate the valley and communities downstream. A major hazard of this is that the removal of such a large amount of material has the potential to trigger an explosive eruption of the geothermal system and renew volcanic activity. Although events of this size are infrequent, there is a significant risk to the communities downstream of the complex. 


\section{Introduction}

In this paper, analyses on slope stability of Mount Meager will be carried out through numerical modelling to identify areas of possible future failure and conditions needed for failure to occur. Mapping of various areas of the Mount Meager Volcanic Complex (MMVC) was undertaken to identify other areas of possible future failures using Google Earth. Numerical modelling of profiles through Mount Meager allows determination of unstable areas and possible failure planes. Estimates of the volume of material that could be generated can be deduced from these profiles and modelled to calculate the likely extent this material could reach if a failure of that size were to occur. This can then be used to determine the risk to the population of Pemberton Meadows and Pemberton. According to Simpson et al., (2006) there is a possibility that flows greater than $10^{8} \mathrm{~m}^{3}$ can occur at MMVC, however the current risk of a debris flow reaching populated areas is 1 in 2400 years.

The MMVC is a potentially active and very geologically unstable region of the Garibaldi Volcanic Belt in south-west British Columbia (BC), Canada (Fig. 1) (Simpson et al., 2006). The MMVC is a snow and ice covered series of peaks with steep glaciated slopes composed of hydrothermally altered volcanic material (Fig. 2) (Friele \& Clague, 2004; Simpson et al., 2006). These unstable slopes combined with glacial melt and high precipitation levels have the potential for the generation of large debris flows. Holm et al. (2004) investigated landslide activity in nineteen alpine basins in this region and found that the highest concentration of rock slope failures occur in the MMVC volcanics.

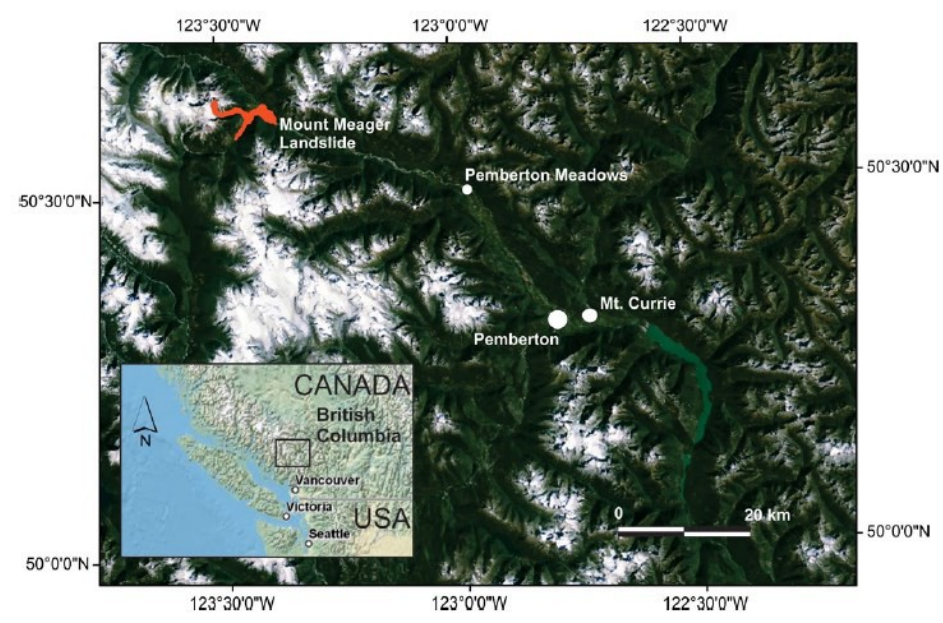

Fig. 1. Location map of the MMVC and 2010 landslide in south-western BC in relation to local communities (from Guthrie et al., 2012) 
Mount Meager is a Quaternary stratovolcano in the south-east of the volcanic complex which rises 2,650 m asl. (Fig. 3) (Friele \& Clague, 2004). Meager Creek runs along the southern limit of the complex and flows into Lillooet River, which runs the length of the northern and eastern valleys surrounding the complex. Mount Meager is possibly the most unstable mountain massif in Canada (Friele \& Clague, 2004; Friele et al. 2008), making Meager Creek Basin one of the most geomorphically active and hazardous areas in the Canadian Cordillera (Bovis \& Jokob, 2000). Although the last known eruption from Mount Meager was approximately 2,360 years BP (Hickson et al., 1999; Bovis \& Jokob, 2000; Simpson et al., 2006; Friele et al., 2008) there is still potential for very explosive eruptions.

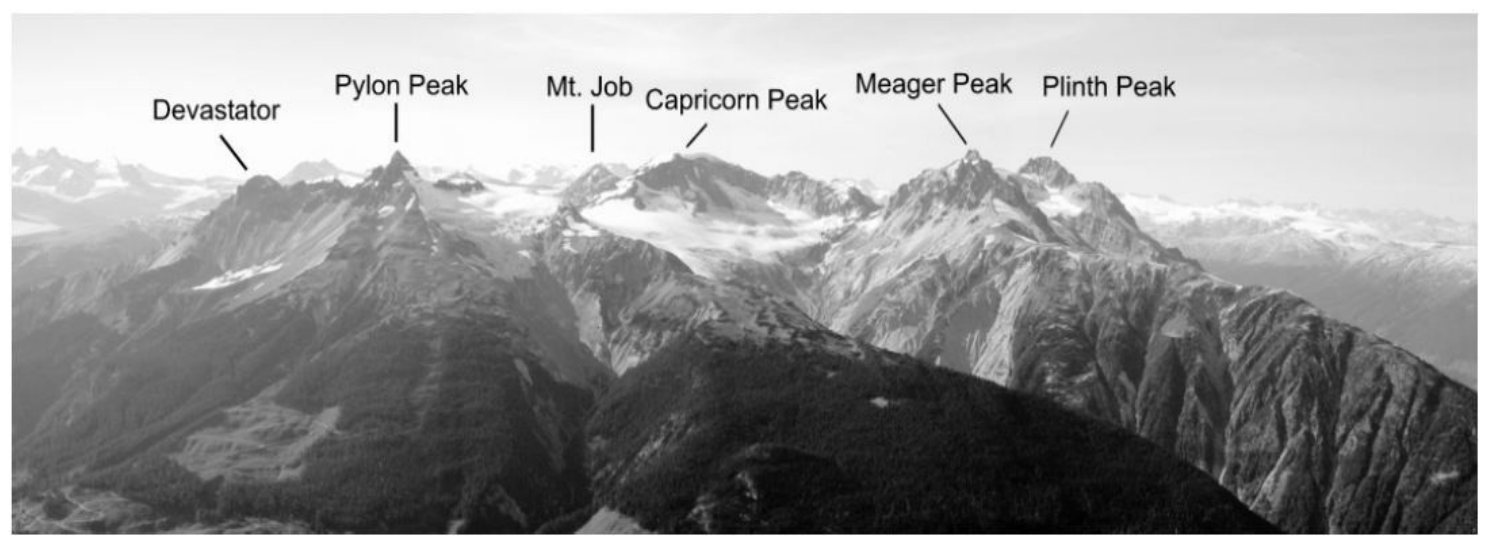

Fig. 2. Main peaks of the MMVC as viewed from the East (from Simpson et al., 2006).

Many landslides and debris flows have occurred in this region, unrelated to volcanic activity. Slope failures are fairly frequent events due to weakening and destabilization of the slopes and climatic conditions. There have been a minimum of twenty five landslides at the MMVC with a volume of $0.5 \times 10^{6} \mathrm{~m}^{3}$ or greater in the last 10,000 years (Guthrie et al., 2012). At least six landslides have formed temporary dams in the last 60 years (Bovis \& Jakob, 2000) which have later failed and caused risk of flooding downstream, the most recent debris avalanche being in August 2010 in Meager Creek. This was one of the largest landslides to have occurred globally since 1945, making it a significant event (Guthrie et al., 2012). The MMVC is therefore a site of interest for analysing stability, with particular focus on Capricorn creek, where most historical failures have occurred.

The Lillooet River flows downstream in Pemberton Valley towards the town of Pemberton. Pemberton is a small town, with a population of around 3,800, located approximately $55-75 \mathrm{~km}$ downstream and with associated rural areas of Pemberton Meadows, with a population of 200 located $32-55 \mathrm{~km}$ downstream of 
Mount Meager (Fig. 1) (Friele et al. 2008). Evidence from drilling in the Lillooet River Valley suggests that at least three volcanic flows with origins somewhere within the MMVC have reached now populated areas of the valley (Friele \& Clague, 2004). Some of this evidence has been investigated further by Simpson et al. (2006), who have found deposits from three large volume $\left(>10^{8} \mathrm{~m}^{3}\right)$ debris flows in the Pemberton Valley and confirmed risk to Pemberton.

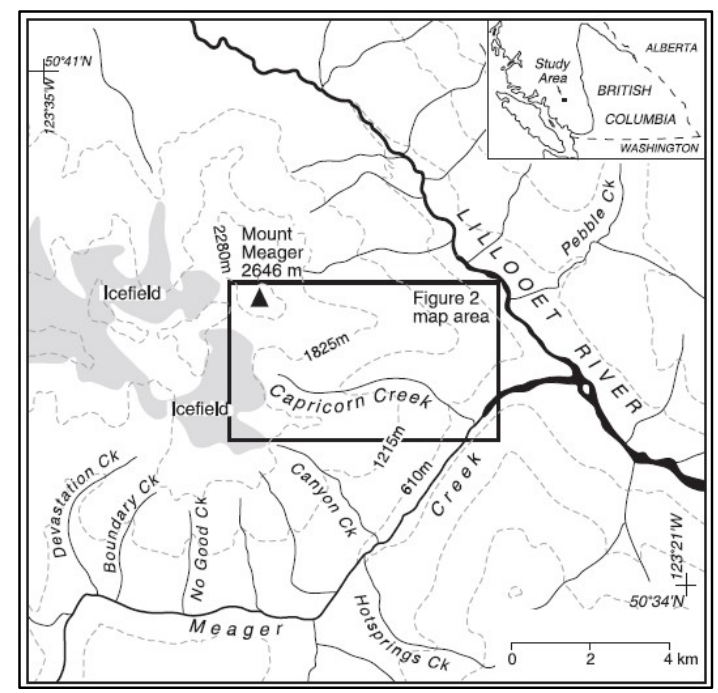

Fig. 3. Mount Meager and site location within the MMVC (from Bovis \& Jakob, 2000).

\section{Geology}

The MMVC composes part of the Coast Mountains located in south-west British Columbia, approximately $150 \mathrm{~km}$ north of Vancouver. It is part of the Garibaldi Volcanic Belt formed as a result of the subduction of the Juan de Fuca plate beneath the North American plate (Hickson et al., 1999). The complex consists of several peaks of volcanic rock ranging in age from Pliocene to Holocene (Guthrie et al., 2012), the youngest of which is Mount Meager. Radiometric ages of the volcanics range from 2.2 Ma (K-Ar) to $2350 \mathrm{BP}$ (radiocarbon) (Hickson et al., 1999).

The volcanic rocks composing the complex range in composition from basalt to rhyolite where the dominant products are from three main periods of volcanism; early and late stage rhyodacite and a middle period of andesite (Read, 1990). There are a wide range of products including basalt, andesite and rhyodacite flows, rhyodacite domes and pyroclastics (Hickson et al., 1999). Read (1990) identified nine volcanic assemblages which compose the bulk of the MMVC, underlain by a granodioritic basement. 
There are three main volcanic assemblages composing Mount Meager; Pylon Assemblage (P3), Capricorn Assemblage (P5) and Plinth Assemblage (P6) (Fig. 4). The Pylon Assemblage, the most extensive unit of the complex, is andesite. Overlying this is the Capricorn assemblage which is weathered rhyodacite. The top $600 \mathrm{~m}$ of Mount Meager is of the Plinth Assemblage. It is a rhyodacite plug/lava dome that forms this peak (Read, 1990). The volcanic material is generally poorly consolidated and prone to catastrophic collapse (Bovis \& Jakob, 2000).

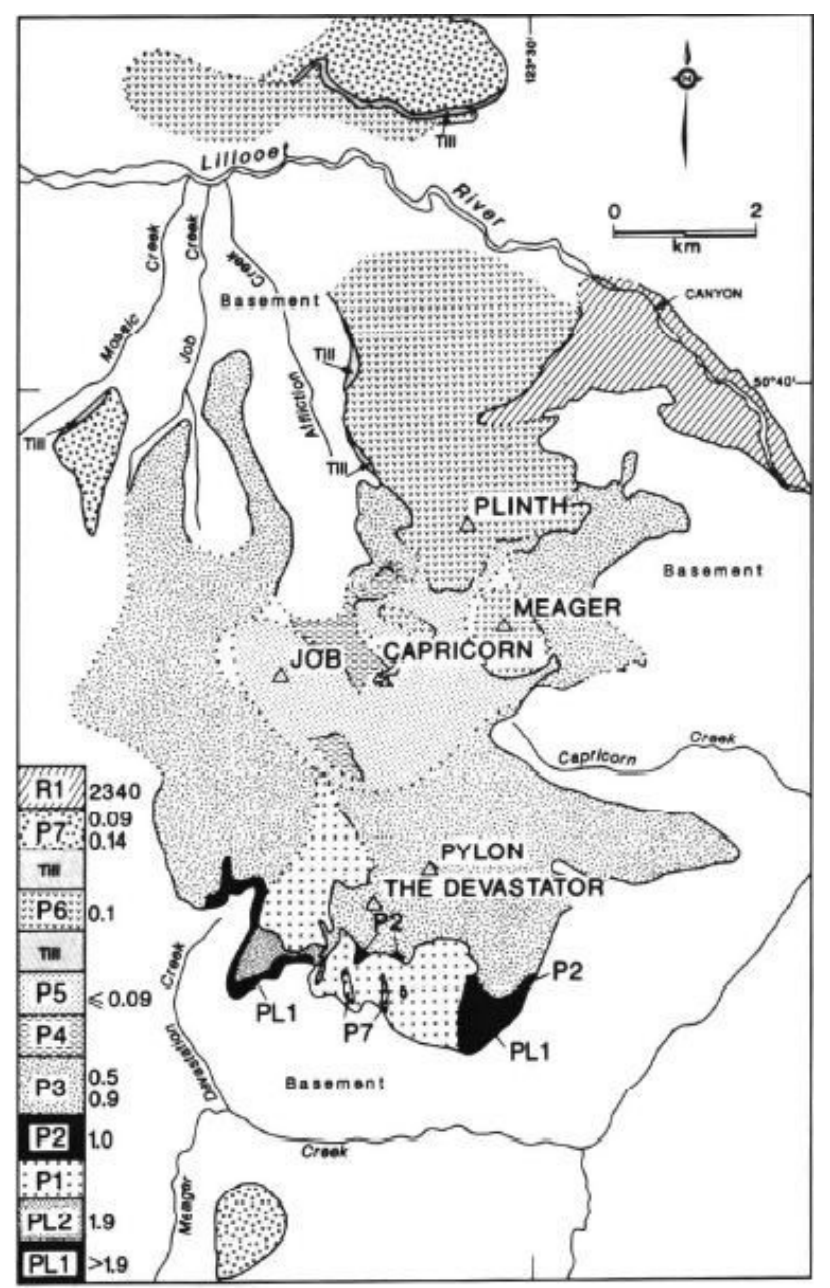

Fig. 4. Geological map of the MMVC. P3 is andesite, P5 is altered rhyodacite and P6 is rhyodacite (See Read, (1990) for details on each assemblage).

The complex is severely affected by hydrothermal alteration, weakening the material and increasing the chances of slope failure (Bovis \& Jakob, 2000; Friele \& clague, 2004; Friele et al., 2008). The volcanics and basement are subject to rapid weathering (Bovis \& Jakob, 2000). The central and northern parts of the complex however, are less altered as there is more ice cover, hence the rock slopes are slightly 
more stable. Mass movement events in the north are therefore less frequent than in the south of the complex, though there have been large debris flows at Job and Affliction Creeks (Jordan, 1994).

There are fifteen small basins which drain the complex, all capable of delivering large debris flows and avalanches (Bovis \& Jakob, 2000). Water seepage is primarily from the basement rock feeding hot springs at various creeks around the site (Read, 1990).

Most of the MMVC was ice covered during the last Pleistocene glaciation. Glacial erosion, stages of advance and retreat and thawing of permafrost have contributed to the large scale destabilisation of the massif (Guthrie et al., 2012). Valleys carved during periods of glaciation show erosional over-steepening and deep-seated movement features (Holm et al., 2004). Glacial retreat has also caused the formation of sackung (sagging) features where slopes have been undercut due to the removal of buttress support. The MMVC basins show greater slope undercutting along Neoglacial trimlines than those in a granitic basin (Holm et al., 2004).

In 1994 Capricorn Glacier covered about 2.9 km$^{2}$ (20\%) of Capricorn Creek basin as opposed to approximately $6.3 \mathrm{~km}^{2}(44 \%)$ during the Neoglacial maximum, as indicated by limit moraines and trimlines. The glacier has retreated by around $3 \mathrm{~km}$ and downwasted by over $200 \mathrm{~m}$ since that time (Bovis \& Jakob, 2000). Devastation Glacier was also much larger, extending $4 \mathrm{~km}$ into Devastation Creek in 1932 (Mokievsky-Zubok, 1977).

Mass movement activity at the MMVC is unusually high. This is due to a combination of steep, high relief areas carved in the weak rocks, humid climate and rapid recession of the glaciers over the last 150 years (Bovis \& Jakob, 2000).

\section{Landslide History}

\subsection{Prehistoric and Historic Activity}

Rock avalanches and debris flows at the MMVC have been dated back as far as 7,900 years BP, with identification of at least fifteen separate events during prehistoric time (Table 1). Most of these occurred at Job Creek in the north of the complex and at the creeks south of the complex around the Devastator and Pylon Peak. Units dated at $2400 \mathrm{BP}$ correlate with the last known eruption of the MMVC 
(Friele et al., 2008). All other failures are believed to have had non-eruptive triggers meaning they were 'cold' mass wasting events (Stewart et al., 2003).

During historic time there have been ten recorded debris flows and rock avalanches, most occurring at Capricorn Creek in the south-east of the complex (Guthrie et al., 2012). A section of Mount Meager failed in July 1998 in Capricorn Creek (Fig. 5). An estimated $1.2 \times 10^{6} \mathrm{~m}^{3}$ of material was displaced after record breaking high temperatures were recorded that same month (Bovis and Jakob, 2000). A glacially de- buttressed slope collapsed leading to a debris flow in Devastation Creek in July 1975 (Holm et al., 2004) after a similar pattern of high temperatures which probably caused extensive snow melt (Bovis and Jakob, 2000). This was another large volume event with $1.2 \times 10^{7} \mathrm{~m}^{3}$ of material released (Friele et al., 2008; Guthrie et al., 2012) which killed four people in Meager Creek (MokievskyZubok, 1977). Guthrie et al., (2012) also documented a smaller failure of $0.5 \times 10^{6}$ $\mathrm{m}^{3}$ from 2009 to the left of the 1998 failure site (Fig. 5).

Debris flows with an estimated total volume of $>10^{5} \mathrm{~m}^{3}$ occurred at Capricorn Creek in 1998, 1972, 1944-45 and 1933-34 according to Bovis \& Jakob (2000) giving a short return period of 17 years for large events. They also found that other large mass movements of unknown magnitude took place in 1909, 1873, 1841 and 1669 as indicated from tree ring records.

The 2010 debris avalanche occurred on the $6^{\text {th }}$ August and was the tenth mass flow with a volume greater than $0.5 \times 10^{6} \mathrm{~m}^{3}$ at the MMVC since 1850, and the sixth largest over the Holocene (Fig. 6) (Guthrie et al., 2012). The 2010 event occurred at Capricorn Creek with the failure of the southern side of Mount Meager, which flowed into Meager Creek and Lillooet River, temporarily damming both rivers (Fig. 7). The volume of material which failed during this event was estimated at $48.5 \times 10^{6} \mathrm{~m}^{3}$ (Guthrie et al., 2012). This was the most recent event. 


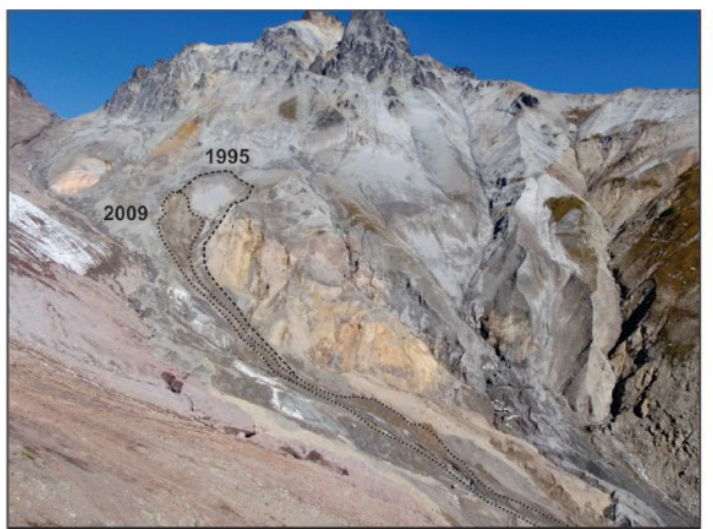

Fig. 5. Detachment zones of the 1998 and 2009 failures on the southern side of Mount Meager (from Guthrie et al.. 2012).

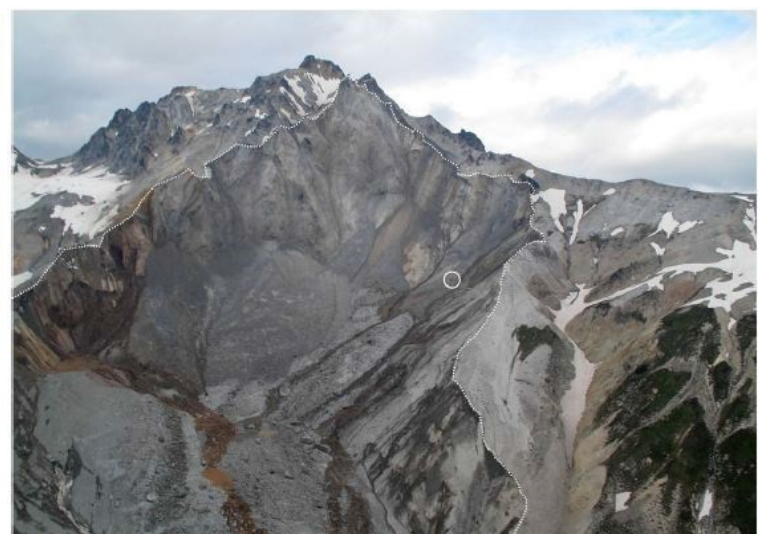

Fig. 6. Detachment zone of the 2010 failure on the southern face of Mount Meager. A helicopter is circled for scale (from Guthrie et al., 2012).

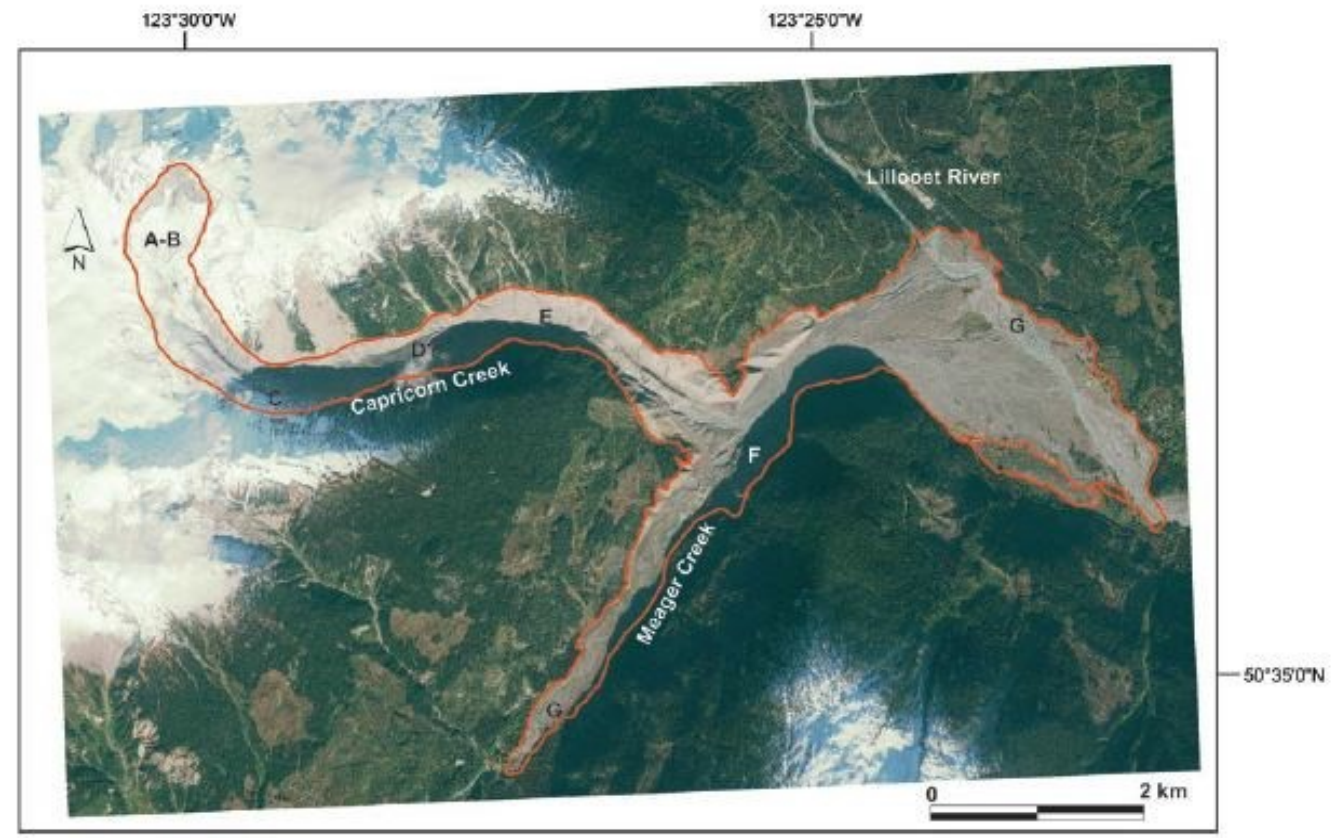

Fig. 7. The 2010 debris flow deposit from Capricorn Creek entering Meager Creek and Lillooet River, damming both rivers (from Guthrie et al., 2012). 
Table 1. All known historic and prehistoric landslides from the MMVC with a volume $\geq 0.5 \times 10^{6} \mathrm{~m}^{3}$ (from Guthrie et al., 2012).

\begin{tabular}{|c|c|c|c|c|}
\hline Event & Source & Date $^{1}$ & $\begin{array}{r}\text { Volume } e^{2} \\
\left(\times 10^{6} \mathrm{~m}^{3}\right)\end{array}$ & Reference \\
\hline \multicolumn{5}{|l|}{ Prehistoric } \\
\hline Rock avalanche/debris flow & Pylon Pk. & -7900 & $450^{*}$ & Friele and Clague (2004) \\
\hline Rock avalanche/debris flow & Job Ck. & -6250 & $500^{*}$ & Friele et al. (2005) \\
\hline Rock avalanche/debris flow & Capricorn $\mathrm{Ck}$. & -5250 & $5^{*}$ & McNeely and McCuaig (1991) \\
\hline $\begin{array}{l}\text { Rock avalanche/debris } \\
\text { flow/hyper concentrated flow }\end{array}$ & Pylon Pk & -4400 & 200 & $\begin{array}{l}\text { Friele and Clague (2004); } \\
\text { Friele et al. (2005) }\end{array}$ \\
\hline Rock avalanche/debris flow & Job Ck. & -2600 & $500^{*}$ & Friele et al. (2005); Simpson et al. (2006) \\
\hline Pyroclastic flow & Syn-eruptive & -2400 & 440 & Stasiuk et al. (1996); Stewart (2002) \\
\hline $\begin{array}{l}\text { Rock avalanche/outburst } \\
\text { flood/debris flow/hyper } \\
\text { concentrated flow }\end{array}$ & Syn-eruptive & -2400 & 200 & Stasiuk et al. (1996); Stewart (2002) \\
\hline Rock avalanche & Syn- to post-eruptive & -2400 & 44 & Stasiuk et al. (1996); Stewart (2002) \\
\hline Debris flow & Devastation $\mathrm{Ck}$ & -2170 & 12 & McNeely and McCuaig (1991) \\
\hline Debris flow & Job Ck. & -2240 & 1 & Friele et al. (2008) \\
\hline Debris flow & Angel $\mathrm{Ck}$. & -1920 & $0.5^{*}$ & McNeely and McCuaig (1991) \\
\hline Debris flow & Job Ck. & -1860 & 1 & McNeely and McCuaig (1991) \\
\hline Debris flow & Job Ck. & -870 & $9^{*}$ & Jordan (1994) \\
\hline Debris flow & Job Ck. & -630 & 1 & Friele et al. (2008) \\
\hline Debris flow & No Good Ck. & -370 & $5^{*}$ & McNeely and McCuaig (1991) \\
\hline \multicolumn{5}{|l|}{ Historic (age $\mathrm{AD}$ ) } \\
\hline Debris flow & Capricom $\mathrm{Ck}$. & 1850 & 1.3 & $\begin{array}{l}\text { Jakob (1996); McNeely and } \\
\text { McCuaig (1991) }\end{array}$ \\
\hline Debris flow & Capricom Ck. & 1903 & 30 & Jakob $(1996)$ \\
\hline Debris flow & Devastation $\mathrm{Ck}$ & 1931 & 3 & $\begin{array}{l}\text { Carter (1932); Decker et al. (1977); } \\
\text { Jordan (1994) }\end{array}$ \\
\hline Rock avalanche & Capricorn Ck. & 1933 & $0.5^{*}$ & Croft (1983) \\
\hline Rock avalanche & Devastation $\mathrm{Ck}$ & 1947 & 3 & Evans unpublished data \\
\hline Rock avalanche & Devastation $\mathrm{Ck}$ & 1975 & 12 & Mokievsky-Zubok (1977); Evans (2001) \\
\hline Rock avalanche & Mt. Meager & 1986 & $0.5^{*}$ & Evans (1987) \\
\hline Debris flow & Capricorn Ck. & 1998 & 1.3 & Bovis and Jakob (2000) \\
\hline Debris flow & Capricorn $\mathrm{Ck}$. & 2009 & 0.5 & Friele (unpublished data) \\
\hline Rock slide/debris flow & Capricorn Ck. & 2010 & 48.5 & This study \\
\hline
\end{tabular}

1 Prehistoric dates are radiocarbon ages BP. Cited ages are those that closely constrain an event, however, considerable ranges may be present. For more details see Friele and Clague (2004), or the original sources. 2 Volumes denoted by * are the median volume of a wider range.

\subsection{Triggering Mechanisms}

There have been multiple triggering mechanisms recognised at the MMVC. The 2400 BP failures were a result of volcanism at that time. This was a large eruption with tephra reaching as far as Alberta, $530 \mathrm{~km}$ to the east of the eruption vent and multiple associated units in Lillooet River Valley (Hickson et al., 1999). All other identified events have had other triggers, many unknown. The main cause behind recent slope failures around the volcanic complex is a combination of weak rock and de-buttressing due to glacial retreat. Failure of the more altered material can then trigger rock avalanches in the overlying material (Friele \& Clague, 2004). The retreat of ice exposes rock and removes support destabilising the slopes. Climatic conditions also appear to have a large impact on stability as most failures occur during warm periods when snow and ice melt is at its highest, for example, the 1998 and 2010 failures both occurred in summer, after a period of high temperature. This 
infiltration of water combined with de-buttressing and the effect of the hydrothermal system beneath the Complex causes intense weathering and alteration of the rocks, weakening them. The 1998 event can be linked with a specific climatic trigger, however evidence shows that glacial down-wasting and debuttressing since the end of the Neoglacial maximum were important precursors (Bovis \& Jakob, 2000). For prehistoric failures, which do not correlate with an eruption, the triggering mechanism(s) is/are harder to determine. The $7900 \mathrm{BP}$ and 4400 BP events from Pylon Peak had an estimated combined volume of 6-7 $x$

$10^{8} \mathrm{~m}^{3}$. The triggers for these events are unknown, but may have resulted from earthquakes or magma upwelling at shallow depths. They may also have occurred without a specific trigger and due to the progressive weakening of rocks (Friele \& Clague, 2004).

\section{Study Site}

Capricorn Creek is one of the largest basins to drain the southern flank of MMVC. It enters Meager Creek at a right angle which promotes deposition and blockage as opposed to downstream transportation. This means that Meager Creek is very susceptible to creating landslide dams (Bovis \& Jakob, 2000).

Mount Meager itself is a rhyodacite plug forming the top $600 \mathrm{~m}$ of the peak, with steep slopes (Fig. 8). Surrounding the plug is altered rhyodacite, which overlays andesite flow layers. Below this is the granodiorite basement. These are the four main units composing the bulk of the site of interest and focus. There is also a lot of loose debris and glacial material around Mount Meager and down Capricorn Creek into Meager Creek.

Meager Creek is filled with deposits from various debris flows and rock avalanches to a depth of over $250 \mathrm{~m}$ (Read, 1990). There are seven creeks from the southern side of the MMVC which feed Meager Creek with material from the complex. These are, from left to right, Devastation Creek, Boundary Creek, No Good Creek, Angel Creek, Pylon Creek, Canyon Creek and Capricorn Creek (Fig. 9) (Simpson et al., 2006). The most active of these is Capricorn Creek, with at least six events of $0.5 \times 10^{6} \mathrm{~m}^{3}$ or greater in volume since 1850. Devastation Creek appears to be the next most active creek, with three large landslides within the past century (Guthrie et al., 2012).

Due to this high frequency of events at Capricorn Creek, Mount Meager is the main focus of this study, analysing its stability and possible future events in this area. 


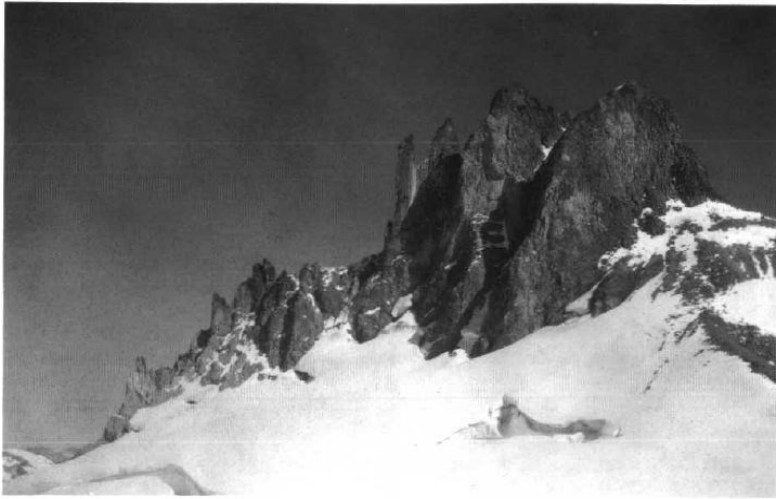

Fig. 8. Rhyodacite plug forming the peak of Mount Meager (from Read, 1990)

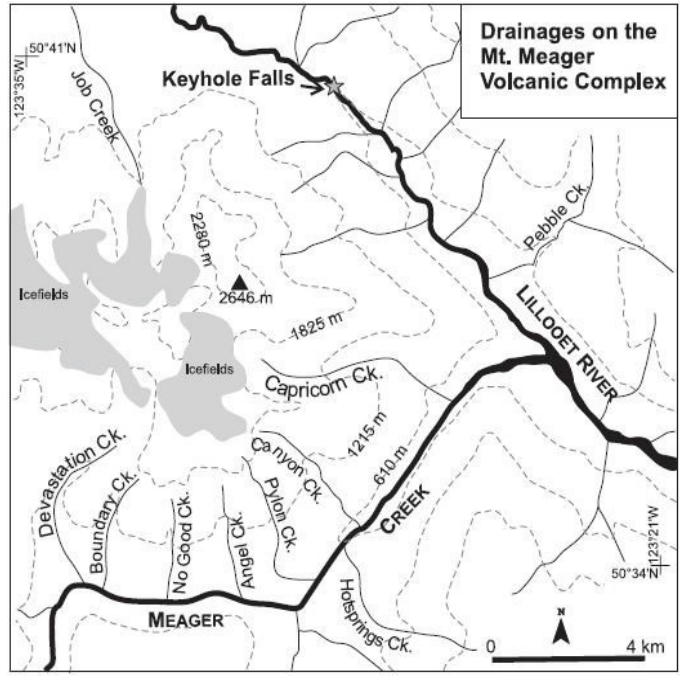

Fig. 9. Creeks on the southern side of the MMVC entering Meager Creek (from Simpson et al., 2006)

\section{Mapping}

Preliminary mapping of the entire complex using Google Earth shows there are many more sites of possible instability, and areas which appear to be already failing (Fig. 10). Images show there are bulges, fractures and slumping, terrace-like features around the complex which is supported by literature describing sackungs at various locations

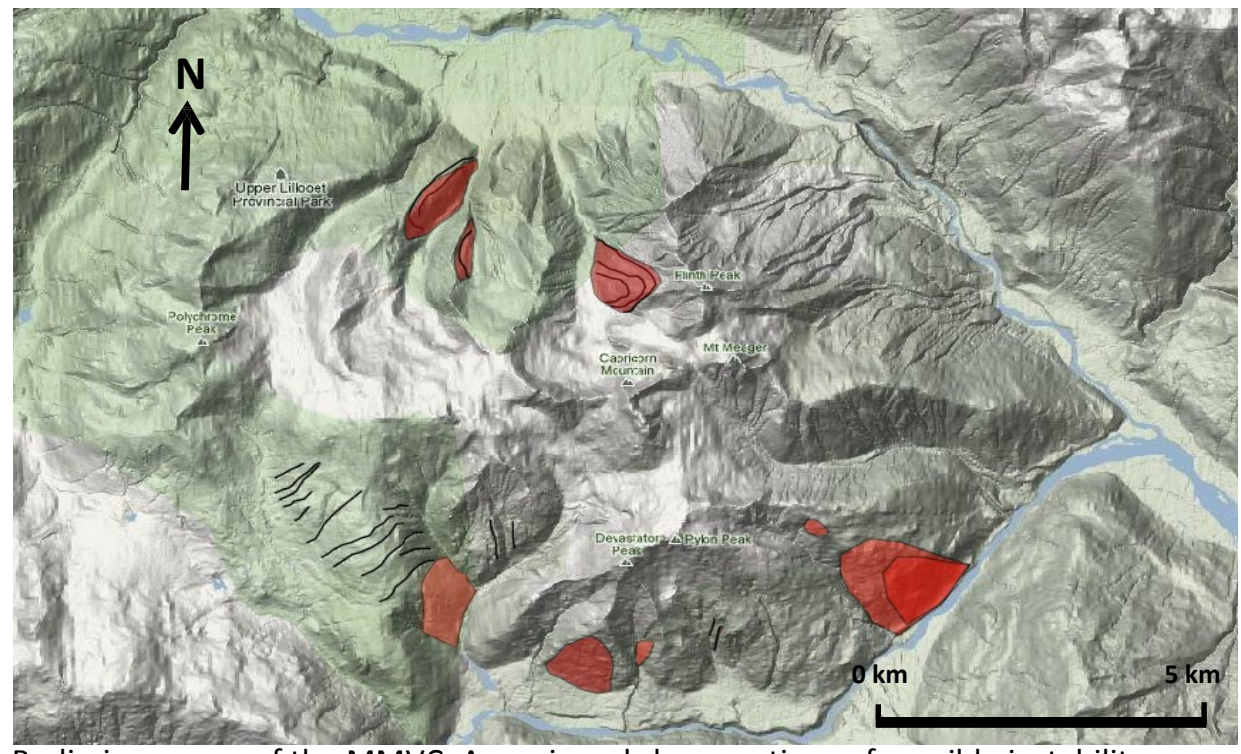

Fig. 10. Preliminary map of the MMVC. Areas in red show sections of possible instability as seen using Google Earth and areas that are already failing as found in literature. The literature describes most of the same areas as found when mapping, validating the use of Google Earth as a useful tool for detecting areas which appear unstable. Black lines show fractures and terracing (Image from Google Earth, 2010). 


\subsection{Features Indicating Movement}

Sackungs are sagging features on slopes which indicate slow, deep-seated, rockmass creep (Fig. 11) (Hewitt et al., 2008). Bovis \& Evans (1996) suggest that sackungs may also be without a deep-seated shear surface. Tension cracks, grabens and antislope scarps are features that are attributed to sackung type progressive movement (Bovis \& Evans, 1996; Bovis \& Jakob, 2000). Large scale slope sagging has been recognised in hard, fractured, crystalline, intrusive rocks like in the coast Mountains and have been commonly identified on steep slopes and flanking detachment zones around the MMVC, including Affliction, Capricorn and East and West Devastation Creeks (Bovis \& Evans, 1996). This implies these features are likely precursors to failure. Evidence to support this was seen in Capricorn Creek, where extensive tension cracks and scarps were observed adjacent to the 1998 failure site. These cracks and scarps would have facilitated rapid infiltration of meltwater in late July (Bovis \& Jakob, 2000). Tension cracks in Capricorn Creek, as well as various other failure locations, are still visible in images from Google Earth.

Anti-slope scarps appear to result from toppling (Bovis \& Evans, 1996) and be best developed in areas of glaciation where there has been a rapid change in stress (Bovis, 1982). This is consistent with the idea that sackungs result from de-buttressing of slopes (Bovis, 1990). These scarps may be antithetic faults for deep-seated failure planes.

\subsection{Affliction Creek}

Affliction Creek, in the north-west of the MMVC, is split into two tributaries within the Complex, which join and flow as one into Lillooet River. On the western side of each tributary there is an area where slope sagging appears to be taking place (Fig. 12). The sloping scarps can clearly be seen using Google Earth. This would indicate slow movement such as rotational creep.

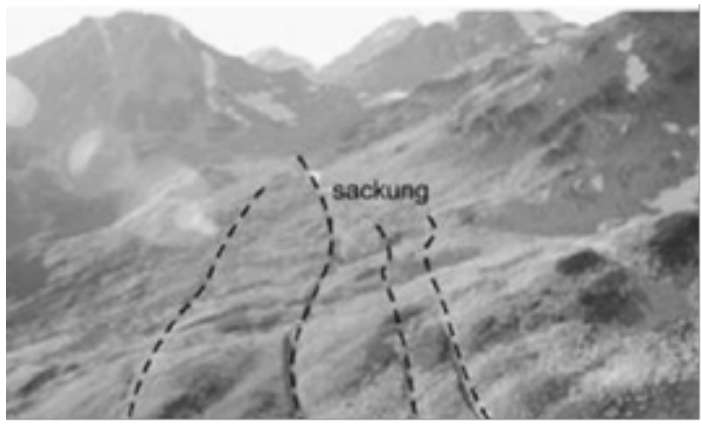

Fig. 11. Sackungs (anti-slope scarps and trenches) in Lillooet River Valley, north of Pemberton (from Hewitt et al., 2008).

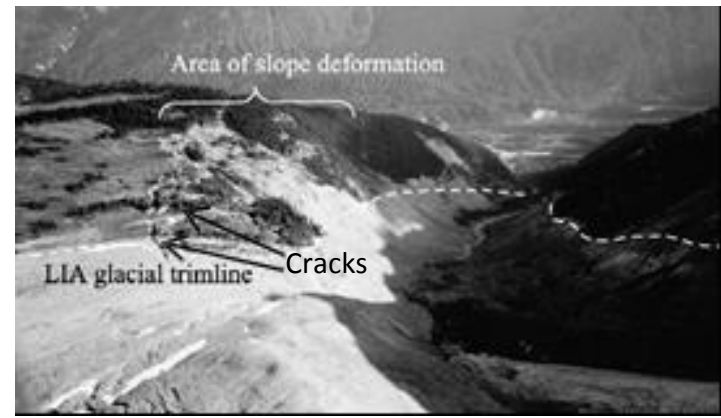

Fig. 12. Slope sagging (sackungs) at Affliction Creek in relation to the LIA glacial trimline. View to the north (from Holm et al., 2004). 
This indication is supported by Bovis (1982; 1990), who mapped features at one of these sites at Affliction Creek, and found clear evidence of anti-slope scarp development since the Neoglacial maximum in the mid- $19^{\text {th }}$ Century. Since this time they suggest there has been approximately $100 \mathrm{~m}$ of glacial down-wasting in the Creek, which likely affects slope stability through the removal of lateral support from over-steepened rock faces. Ground motion vectors indicate rotational sagging and the amount of material estimated to be affected at Affliction Creek is $3 \mathrm{x}$ $10^{7} \mathrm{~m}^{3}$ (Bovis, 1990). Evidence from studies by Bovis (1990) suggests that tension cracks started in the northern section of the study site and propagated southwards. This is consistent with initiation by glacial down-wasting as glacial retreat occurred from north to south.

\subsection{Devastation Creek}

Terraces can be seen within the material in East Devastation Creek. The ridge to the west of Devastation Creek displays numerous linear fractures, many of which are perpendicular to the majority. The fractures follow weaker planes in the rock down to the valley. Images show snow collected in these fractures, so may be expanded as a result of freeze-thaw processes. The block at the end of the ridge, directly above the valley, displays what appear to be a series of anti-scarps (Fig. 13). If this end block failed, the rock fall would likely dam Meager Creek.

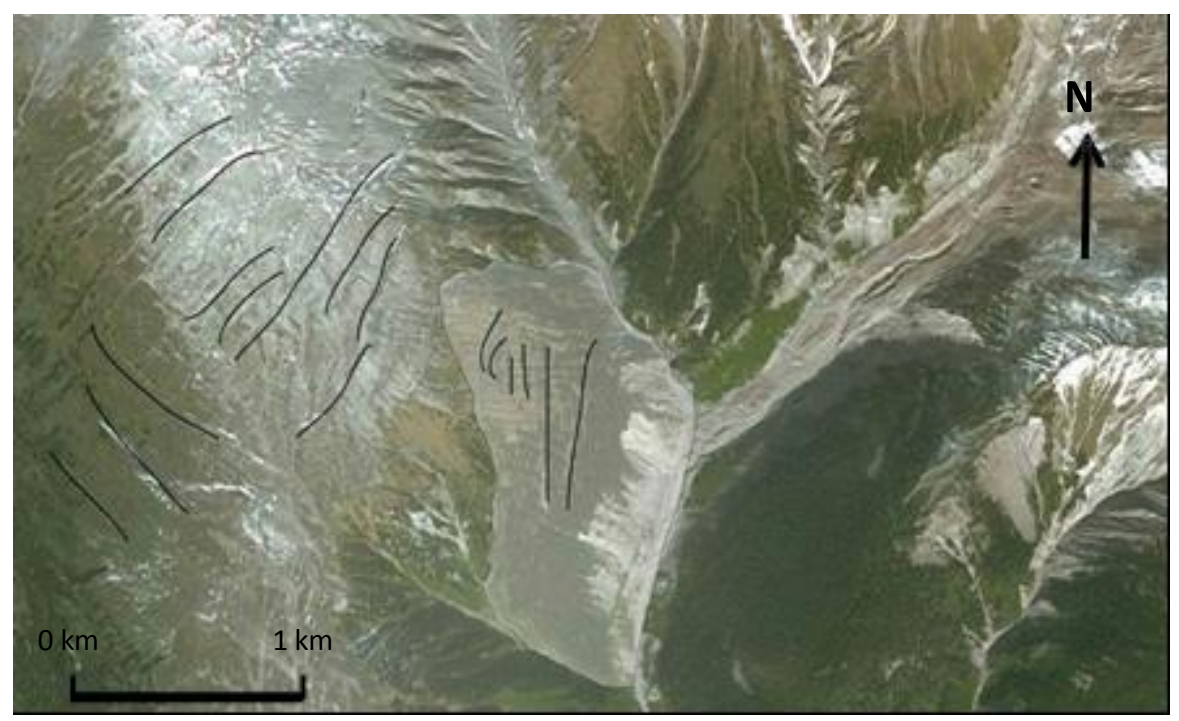

Fig. 13. West Devastation Creek showing the block at the end of the ridge which appears to be a site of instability. The black lines within the block section show prominent anti-slope scarps suggesting slope sagging and progressive movement. The other black lines show the main fractures at higher elevation of the ridge (Image adapted from Google Earth 2010). 
Literature supports that Devastation Creek is also affected by slope movement. The ridge displays a prominent discontinuous series of anti-slope scarps, which cover a $1.1 \mathrm{~km}$ wide area, extending for approximately $2.6 \mathrm{~km}$, roughly parallel to contours. Failures have led to the recession of Devastation Creek and the undercutting of slopes. These steep undercuts have caused the slopes to become susceptible to slow gravitational movement, creating numerous scarps (Bovis \& Evans, 1996). The material composing the Devastator Assemblage underlies numerous locations where past landslides have occurred. Potential instabilities still remain in this material (Friele \& Clague, 2004). East Devastation Creek is concerning as it is undergoing small scale settlement movements and is underlain by altered pyroclastic rocks and flows (Friele et al., 2008). The presence of linears adjacent to the headscarps of previous failures indicates there is potential for catastrophic rock failures in the vicinity of slopes traversed by these linears (Bovis \& Evans, 1996).

\subsection{Job Creek}

Job Creek is situated in the north of the complex. Preliminary mapping shows there to be deformation on the Eastern side of the creek. The deformation appears to have formed a slight bulge on the western side of Plinth Peak (Fig. 14).

Job Creek is composed of hydrothermally altered rocks and is one of the sources for major prehistoric failures and edifice collapses (Friele et al., 2008). This is thought to be the origin for one of the three major debris flow deposits in Lillooet River Valley, identified by Simpson et al. (2006). There are many large unstable masses within the MMVC capable of generating future edifice collapse, one of the most likely of these sites to fail being the eastern side of Job Creek (Friele et al., 2008).

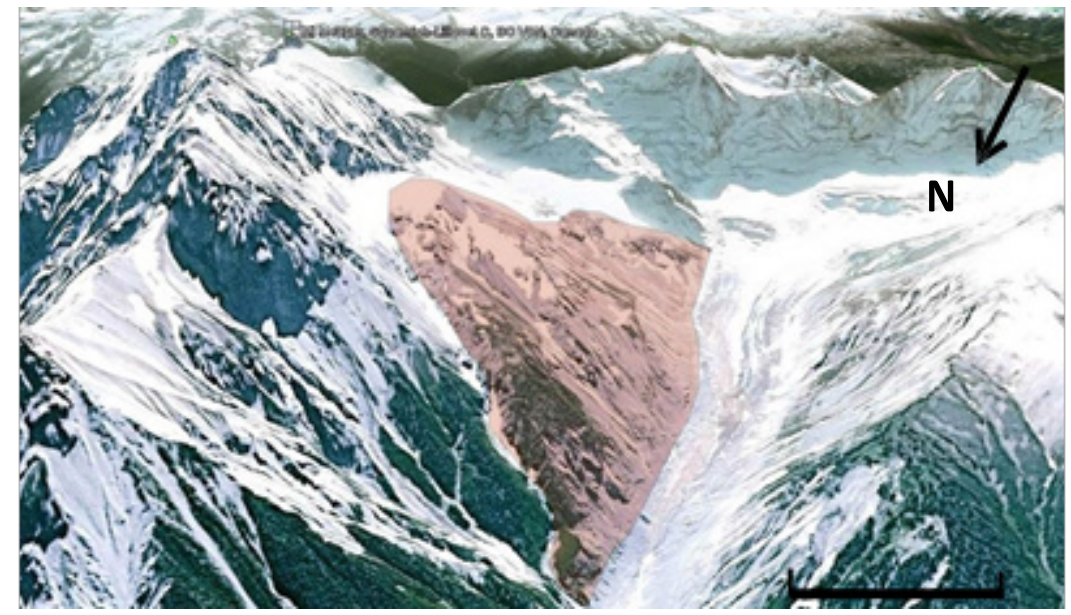

Fig. 14. Deformation in Job Creek, on the western flank of Plinth Peak. Mount Meager can be seen in the background behind Plinth (Image adapted from Google Earth 2010). 


\subsection{The Flanks of the Devastator and Pylon}

There are several areas of possible future failures identified through mapping of the Complex. Areas where scarps and/or terraces are present include, from left to right, the west side of Boundary creek (Fig. 15), a section between Boundary Creek and No Good Creek (Fig. 15), the east side of No Good Creek (Fig. 16), the east side of Angel Creek (Fig. 16) and the east side of Canyon Creek (Fig. 17).

According to Holm et al. (2004), Angel Creek will likely experience a future increase in debris flow activity as the basin reaches its storage capacity (Fig. 18). Friele et al. (2008) state that Angel Creek is a major source of edifice collapse and due to its composition of hydrothermally altered material the flanks of Pylon are likely sites for future failures.

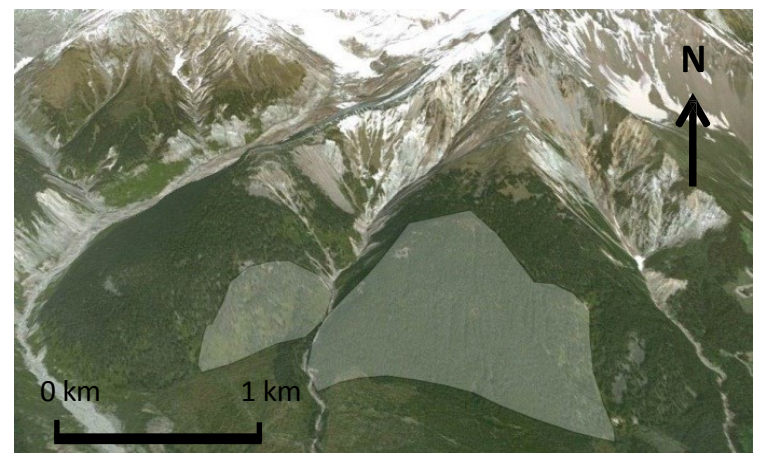

Fig. 15. Devastation Creek (left), Bounday Creek (center) and No Good Creek (right) below the Devastator Peak. Shaded sections are areas of possible future failure, where slumping appears to be occurring. (Image adapted from Google Earth 2010).

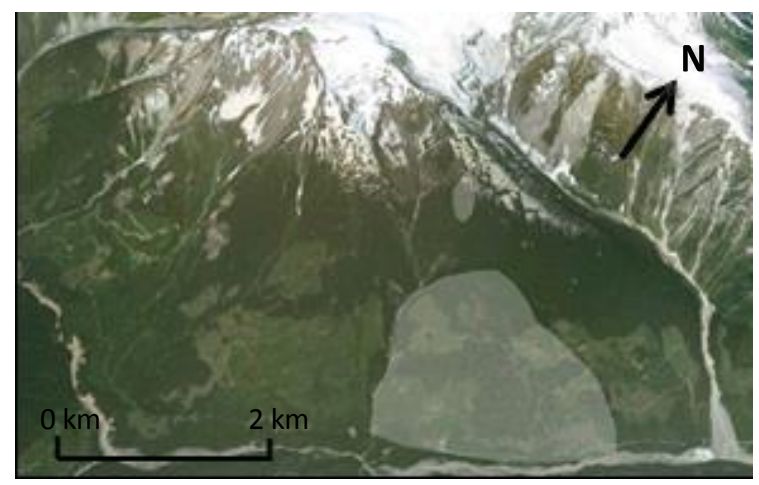

Fig. 17. The shaded areas are possible future failures based on slumping of the eastern side of Canyon Creek, below Pylon Peak (Image adapted from Google Earth 2010).

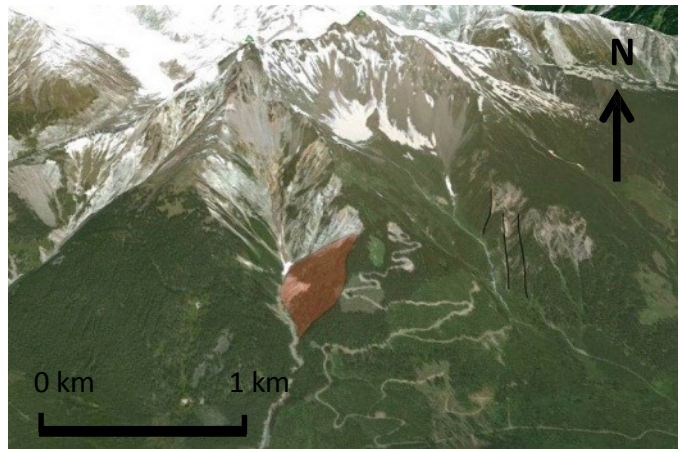

Fig. 16. Slumping indicating possible future failure (shaded area) on the eastern side of No Good Creek, below the Devastator and terracing (black lines) on the eastern side of Angel Creek, below Pylon Peak (Image adapted from Google Earth 2010).

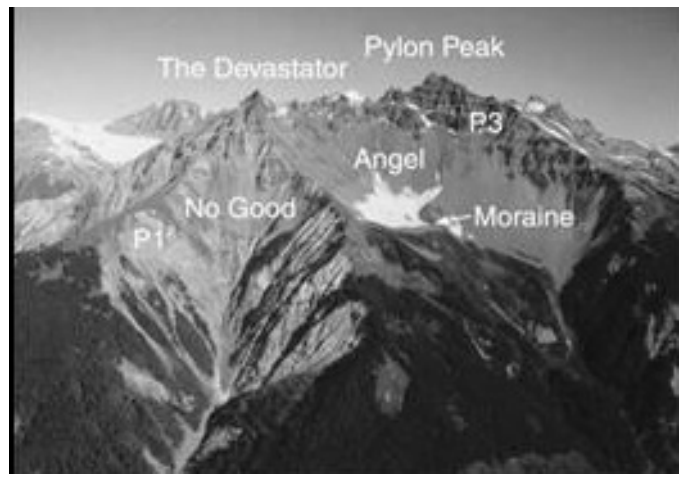

Fig. 18. Angel Creek is expected to have an increase in debris flow activity as the basin reaches its storage capacity (from Friele \& Clague, 2004). 


\subsection{Capricorn Creek}

Cracks and fractures can be identified within Capricorn Creek and around Mount Meager. There are numerous scars in and around the detachment zones where previous failures have occurred.

Tension cracks and scarps were observed around the detachment zone of the 1998 failure, as previously mentioned, (Fig. 19) in photographs dating back to 1948. This indicates there was a period of 50 year of progressive slope movement prior to failure (Bovis \& Jakob, 2000). Bovis \& Evans (1996) stated that there were on-going gravitational slope movements at Capricorn Creek which, like at Devastation Creek, implies a potential for future rock failures in the area surrounding slopes traversed by linears. Failures have occurred in Capricorn Creek three times since then, in 1998, 2009 and 2010.

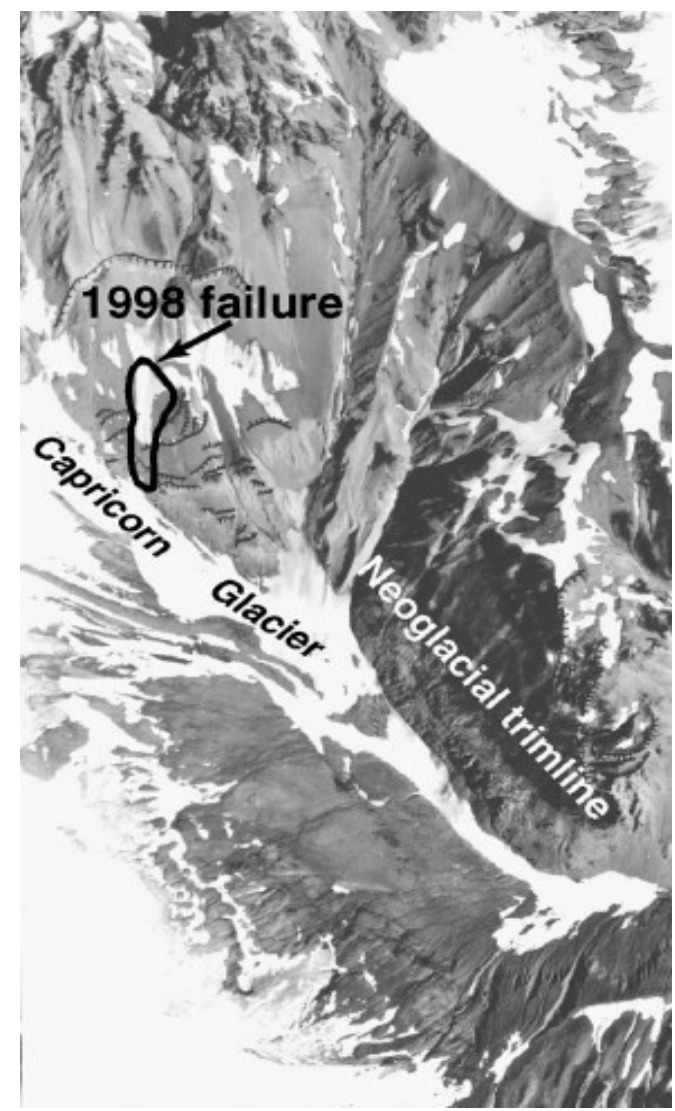

Fig. 19. Black toothed lines show anti-slope scarps and tension cracks around the detachment zone of the 1998 failure of Mount Meager (from Bovis \& Jakob, 2000). 


\section{Methodology}

\subsection{Creating the Profiles}

The aim of modelling was to determine the effects of infiltration on slope stability, with the amount of annual infiltration as the varying parameter. Infiltration was chosen as the focus as precipitation appears to be the cause of most landslides in BC (Jakob \& Lambert, 2009).

The slope stability of Mount Meager was analysed using two cross sections through the peak and leading down to either Lillooet Valley or Meager Creek. The Digital Elevation Model (DEM) used was ASTER image derived from the USGS database via Earth Explorer (http://earthexplorer.usgs.gov/). The image was taken $17^{\text {th }}$ October 2011, 14 months after the most recent failure of the peak. The DEM was imported into ENVI (a Geographical Information System (GIS) program) where the profiles were taken. The directions of the profiles taken ran North - South (N-S) into Meager Creek and South West - North East into Lillooet River Valley. These profiles were each imported into Rocscience's Slide 6.0, where the stability was modelled. Slide 6.0 is one the most comprehensive slope stability analysis software currently available. There are many options and parameters that can be programmed and tested so most conditions acting on, or affecting a slope can be modelled and computed. Once imported, the external boundary was traced and scaled. The vertical scale was obtained from the ENVI profiles. The base of the Complex starts at around $500 \mathrm{~m}$ asl and reaches around 2,600 m.

\subsection{Modelling}

The rocks modelled were determined from geological maps in Read (1990) and Friele \& Clague (2004), dependant on which assemblages the profiles passed through. The material boundaries for the southern half of the Complex were determined using the map in Friele \& Clague (2004), as the topographic contours were also displayed. This was in correlation with other literature which found that the basement-volcanic rock contact was high $(1,500-2,000 \mathrm{~m})$ in Capricorn Creek, and also in Affliction Creek and Canyon Creek (Jordan, 1994; Bovis \& Evans, 1996). The elevation of the material boundaries in the northern half were estimated using Read (1990). The external geology was verified in some places using Google Earth images and photographs from the field where basement rock and flow layers could be identified. Each layer was assigned a material. No profiles or information regarding the internal structure of the Complex were found. The internal structures of the models are therefore assumed (Fig. 20). 


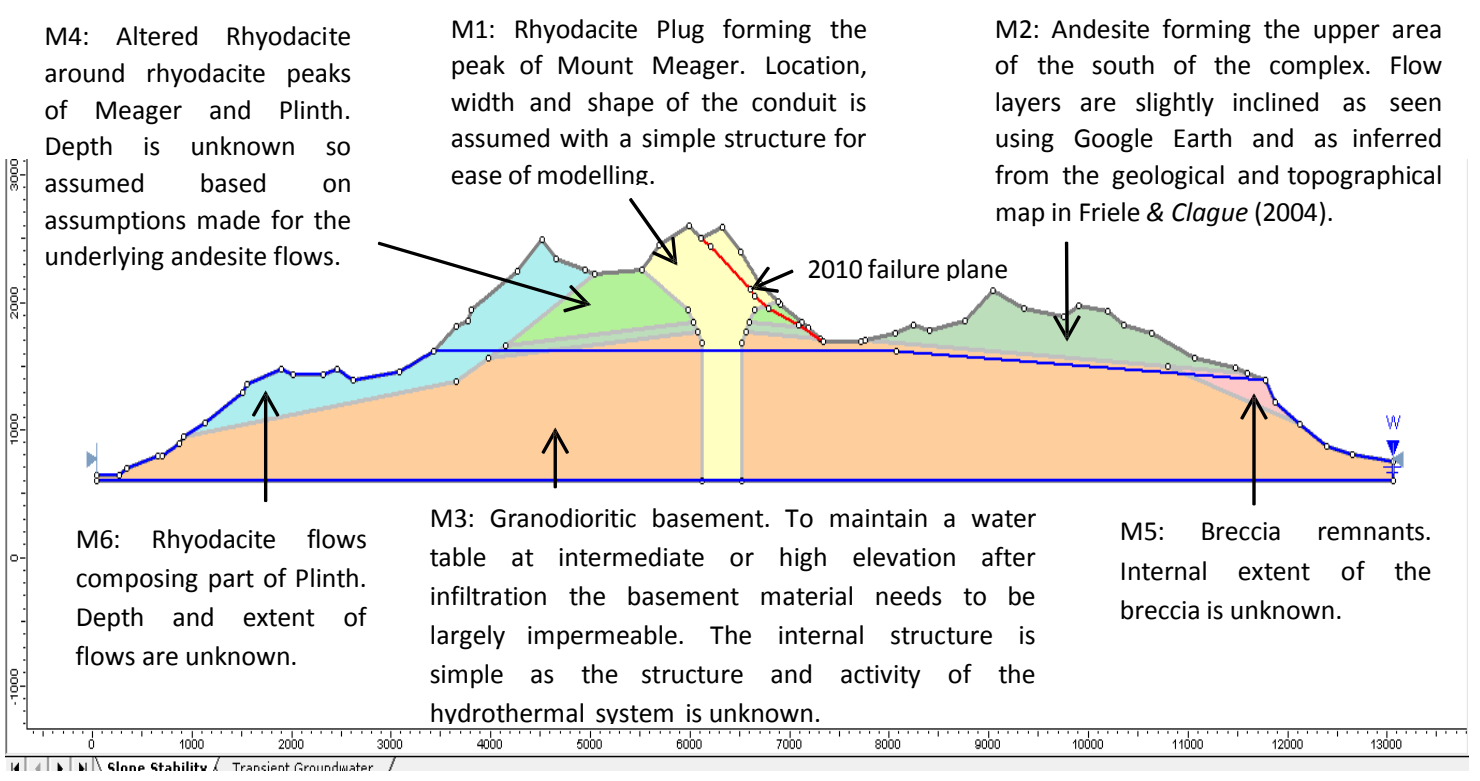

Fig. 20. Model and assumed internal structure for the N-S profile through Mount Meager. Each material is labelled along with the 2010 failure plane.

When classifying a material it is important to identify from which background it is being assessed. From a volcanological viewpoint all materials modelled (rhyodacite, andesite, granodiorite, etc.) are categorised as rocks. However, from a geomechanical viewpoint the strength and consistency of the material could categorise them differently, for example, if these materials are disintegrated they have a more soil like structure and would behave more like a soil. Therefore a strength model of generalised Hoek-Brown (rock) was assigned only to the rhyodacite and Mohr-Coulomb (soil) was assigned to all other material due to alteration.

\subsection{Back Analysis}

To test and verify the material properties and parameters used a back analysis was conducted. This allowed verification for accurate and realistic future modelling. The back analysis used the model to ensure failure of an already known failure plane. The most recent failure of Mount Meager was in August 2010, so various values were tested for each material to determine a structure that modelled that failure. The profile used ran N-S through Mount Meager and across Capricorn Creek passing through the failed slope face. The profile was taken using a DEM image from 2011, which therefore showed the current topography. To form the profile from before 2010, data from Guthrie et al., (2012) was used to reconstruct the topography. Parameters were changed and tested until conditions were met where 
failure occurred along the exact failure plane required.

\subsection{Project Settings}

In the project settings, under the general section, the stress units were set to 'metric', the time units set to 'years' and the permeability units to 'meters/second'. The direction of failure was selected as left to right. The method selected was Bishop Simplified. This is a commonly used method which is typically applied to irregular, non-circular, non- rotational surfaces (Hungr et al., 1989), and is therefore best applicable to the specified failure plane for 2010. In the groundwater section the method was set as 'water surface'. The advanced box was checked and transient groundwater selected. The MMVC is likely to have low permeability materials, causing excess pore pressure due to slow dissipation, therefore transient groundwater analysis is required to simulate these effects (Rocscience, 2010). Transient stages were then set to 11 representing years 2000 to 2010, with each one selected to calculate the Factor of Safety (FOS). The sensitivity analysis option was selected under the statistics section.

Under surface options, a non-circular surface type was selected, with a block search method. This method determines the FOS for a specified block, with a specific failure plane created, therefore being the ideal method to use for the 2010 failure plane in the back analysis. The block search method can only be used for non-circular slip surfaces and works well for multi-material models.

\subsection{Material Properties}

The materials used were determined from geological maps and descriptions in Read (1990). For the N-S section there were six materials modelled; the rhyodacite plug (Material (M)1), andesite (M2), granodiorite (M3), altered rhyodacite (M4), breccia (M5) and Plinth rhyodacite (M6). The unit weight of each material was set to $20.5 \mathrm{kN} / \mathrm{m}^{3}$. This was the value found from the 1998 debris flow deposit by Bovis \& Jakob (2000), who considered the sedimentary characteristics of the deposit to be representative of the material properties at the time of deposition. The strength type for M1 and M6 was set as Generalised Hoek-Brown, and the other four materials as Mohr-Coulomb. As M1 is a plug and M6 is in the northern, less altered part of the Complex, the material is expected to be less weathered than the other materials hence slightly stronger. The other materials are classed as soils as they are subjected to more weathering and hydrothermal alteration and are therefore broken and fragmented as opposed to just fractured, having a more soil- 
like consistency. The strength parameters (e.g. Uniaxial Compressive Strength (UCS), Geological Strength Index (GSI), cohesion and phi) were chosen using Rocscience's RocData 4.0.

With the exception of M6, which is more intact and solid as opposed to altered, all materials have GSI values within the range for disintegrated or blocky structure and poor surface conditions. M6 has been classified as being blocky with good/fair surface conditions. The Intact UCS for M6 is at the lower end of the range for rhyolite. M3, M4 and M5 have been given UCS values in the range of highly weathered or altered rock. M1 and $M 2$ have a slightly higher value falling into the next category of rocks that can be easily indented with a firm blow (Table 2). M2 needed to be slightly stronger than M3 as according to Friele \& Clague (2004) the flow layers of Pylon Peak are less altered than the base rock. These ranges of parameter values are justifiable based on literature describing the weakness and alteration of the material composing the complex (Bovis \& Jakob, 2000; Friele \& Clague, 2004; Friele et al., 2008).

\subsection{Water Table}

As there appears to be no seepage faces at high elevation within the MMVC, Jamieson \& Freeze (1983) suggest the water table lies at an intermediate elevation. In the Slide models the water table has an intermediate position being placed at an elevation of $1,620 \mathrm{~m}$, remaining below the surface until reaching the edge of the Complex.

\subsection{Hydraulic Properties}

The hydraulic properties are set under the Transient Groundwater tab. The hydraulic conductivities (Ks) of the materials required a lot of trial and error to obtain the desired effects on the water table and FOS at the right time. The hydraulic conductivity values (Table 2) for M2 and M4 was set at $1 \times 10^{-7} \mathrm{~m} / \mathrm{s}$ as suggested for volcanic material by Jamieson \& Freeze (1983), using the Van Genuchten parameters for volcanic sand. This value however, did not have the effect needed if used for $M 1$, and neither did their value for the granodioritic basement. For M1 and M6 (both being rhyodacite) the value given was slightly lower $\left(5 \times 10^{-8} \mathrm{~m} / \mathrm{s}\right)$, making the material more impermeable and using the simple model. The value used for $\mathrm{M} 3$ was of low permeability $\left(3.17 \times 10^{-13} \mathrm{~m} / \mathrm{s}\right)$, in the range of unweathered marine clay (http://web.ead.anl.gov/resrad/datacoll/conuct.htm). The Van Genuchten parameters for clay were chosen. M5 was given a hydraulic classification of coarse sand with a hydraulic conductivity of $1 \times 10^{-3} \mathrm{~m} / \mathrm{s}$. 
Table 2. Summary of the main parameters and values used for all materials modelled in Slide.

\begin{tabular}{|c|c|c|c|c|c|c|c|}
\hline Material & $\begin{array}{l}\text { Unit } \\
\text { Weight } \\
\left(\mathrm{kN} / \mathrm{m}^{3}\right)\end{array}$ & Strength Type & GSI & $\begin{array}{l}\text { UCS } \\
\left(k N / m^{2}\right)\end{array}$ & $\begin{array}{l}\text { Cohesion } \\
(\mathrm{MPa})\end{array}$ & $\begin{array}{l}\text { Phi } \\
\text { (degrees) }\end{array}$ & $\mathrm{Ks}(\mathrm{m} / \mathrm{s})$ \\
\hline M1 & 20.5 & Generalised Hoek-Brown & 25 & 6000 & - & - & $5 e-8$ \\
\hline M2 & 20.5 & Mohr-Coulomb & 30 & - & 1309.24 & 17.61 & $1 e-7$ \\
\hline M3 & 20.5 & Mohr-Coulomb & 28 & - & 1766.78 & 14.88 & $3.17 e-13$ \\
\hline M4 & 20.5 & Mohr-Coulomb & 20 & - & 583.81 & 13.87 & $1 e-7$ \\
\hline M5 & 20.5 & Mohr-Coulomb & 28 & - & 819.6 & 15.33 & $1 e-3$ \\
\hline M6 & 20.5 & Generalised Hoek-Brown & 65 & 100,000 & - & - & $5 e-8$ \\
\hline M7 & 20.5 & Mohr-Coulomb & 15 & - & 83.87 & 9.26 & $1 e-3$ \\
\hline
\end{tabular}

\subsection{Rainfall and Infiltration}

Infiltration is modelled by setting the transient boundary conditions and creating a new function. The type was set to 'vertical infiltration with time'. The number of time stages represents how many years to model for and the infiltration is the amount, in meters per year, entering the groundwater. Once set, the conditions are applied to the required surfaces through selection. The time frame, as mentioned, is from 2000 to 2010. Most precipitation at the MMVC falls as snow. According to Jamieson \& Freeze (1983), the average annual precipitation for Mount Meager is around 2.54 $\mathrm{m} / \mathrm{yr}$, and $14-17 \%$ of this enters the groundwater system. This gives an average infiltration of $0.36 \mathrm{~m} / \mathrm{yr}$. The data for the deviation from the average precipitation was obtained from the Canadian database on climate change (http://www.ec.gc.ca/adsc- cmda/default.asp?lang=en\&n=30EDCA67-1). Using the average value and annual deviations, the annual amount of infiltration for the given time period was calculated and applied.

\subsection{Sensitivity Analysis}

To test the parameters and determine which ones had the biggest impact on the results a sensitivity analysis was conducted (Fig. 21). A range of values for each material parameter was provided and once the model had been interpreted in Slide a sensitivity plot was carried out under the statistics section. This showed a graph of the FOS values for the given range and therefore which material properties have the greatest effect on stability results. The UCS and unit weight of the rhyodacite plug (M1) were shown to have the greatest effect on the FOS. The rhyodacite plug has the greatest influence on stability as it composes the bulk of the failed area. Also, if stronger than the underlying material at the base of the slope it would support its 
own weight, hence a higher UCS would increase stability. The graph also shows the FOS then decreases again as the unit weight increases further as the material is then too heavy to support its own weight.

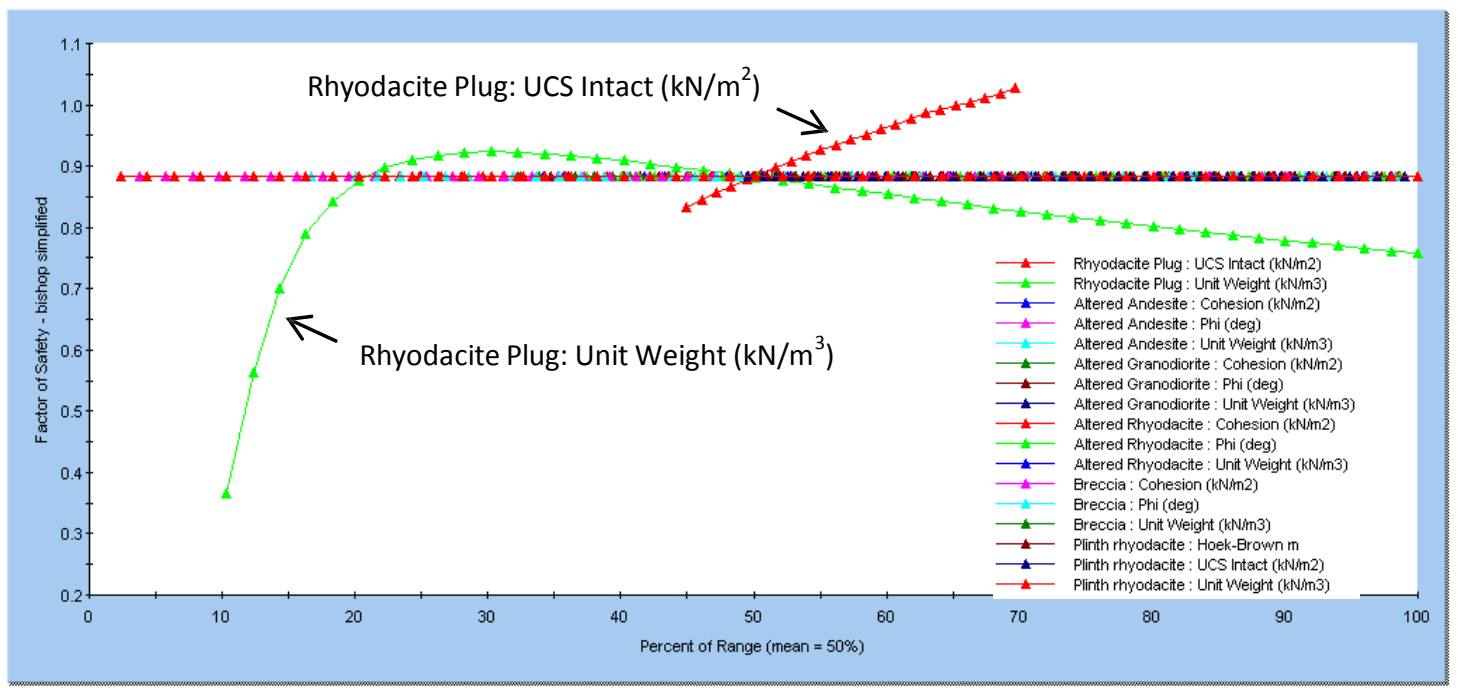

Fig. 21. Sensitivity plot for all material properties and their influence on the factor of safety. The UCS (red line) and unit weight (green line) for the rhyodacite plug have the greatest effect. The other lines define other properties as shown in the legend.

\subsection{Interpretation}

Once all parameters were provided, the model was computed under the analysis tab. Once computation was complete, the model was interpreted displaying the FOS for each of the specified stages as conditions change.

A second model was used showing all possible failure planes for the years 2000-2010 to ensure the weakest part of the section was the location where the 2010 failure actually occurred. Failure in both directions was simulated. The search method was changed from 'block search' to 'grid search', which shows circular slip. Auto-grid was selected to automatically calculate possible failure planes in the direction selected.

\subsection{Forward Modelling}

Once the back analysis was completed, the infiltration was modelled and computed for 2011 and 2012 and projected forward for 2013 and 2014, using extreme infiltration values, displaying any unstable planes along the profile. This showed the areas of greatest weakness, with possible future landslide events, and the section that could likely collapse. In this model the initial water table position was located at higher elevation as seepage could be seen from areas of the 2010 failure plane. This 
projection was also done for the SW-NE profile and one other location within the Complex where instability had been detected through mapping. These sites were in areas of previous landslide activity and displayed either anomalous bulging or sackungs.

\subsection{LAHARZ}

Hazard mapping was undertaken to determine what volume of debris flow would need to be generated in order to reach the town of Pemberton and cause disruption to roads, railways and the population. This was done using a program called LAHARZ, which provides an automated method to map potential areas of inundation. It runs with GIS to create a hazard map showing a lahar-inundation hazard zone for each volume entered (Schilling, 1998). A Natural Colour Landsat TM image of the MMVC was downloaded into ArcGIS to form the basis of the map. A DEM covering the area from the MMVC to Pemberton, obtained from the United States Geological Survey (USGS) database, was also downloaded and cut to a sensible size for lahar analysis to be carried out. Infrastructure data was imported to form layers showing features that could be affected, such as roads, railways and streams, to show flow in the valley, hence likely paths a lahar/debris flow would follow (www.geocomm.com). Fill, flow direction and flow accumulation raster files were generated from the DEM in order to simulate lahar flows. There were eight debris

flows of various volumes, from $10^{6} \mathrm{~m}^{3}$ to $5 \times 10^{8} \mathrm{~m}^{3}$, simulated in Matlab using the program LAHARZ. The ASCII files generated were then converted to raster files and imported into ArcGIS to form layers from which a hazard map for Pemberton was produced. The raster files needed to be projected into the same co-ordinate system as the DEM (WGS_84_UTM) in order to align with the base map and features. Once all the features were in place the hazard map was created in the Layout view.

\section{Results}

\subsection{Factor of Safety}

The results present the FOS values for the back analysis and forward modelling of the Slide models and therefore slope stability, as a result of varied infiltration. The results on the extent of various volumes of debris flows simulated in LAHARZ are also presented along with the ArcGIS inundation hazard map created from flow simulations. 
A slope with a factor of safety (FOS) value $>1.5$ is classified as being stable. Slopes with $1.3<$ FOS $<1.5$ are classed as moderately unstable, $1<$ FOS $<1.3$ as inherently unstable and a FOS $<1$ is at failure (Hoek, 2007). A FOS below 1.3 indicates instability, however with Slide information on the possible types and speed of failure is not provided. To determine this, other forms of modelling and local geological knowledge is required. Many sites within the MMVC are failing, but are slow, mass moving creep failures (e.g. Affliction Creek). These slow moving areas could however, develop into faster, more destructive failures if conditions change, such as increased infiltration, magma upwelling and glacial movements.

\subsection{Before Failure}

In all models for the N-S profile of Mount Meager, the water table reached the surface at stage 1 (first stage of infiltration added). The 'before failure' model, which determines failure along the 2010 failure plane, shows that at the initial stage (before infiltration began) the FOS was at 1.2. When annual infiltration begins, the FOS drops to just above 1 and gradually decreases over the stages down to 0.963 at the final stage (representing 2010) (Fig. 22). 


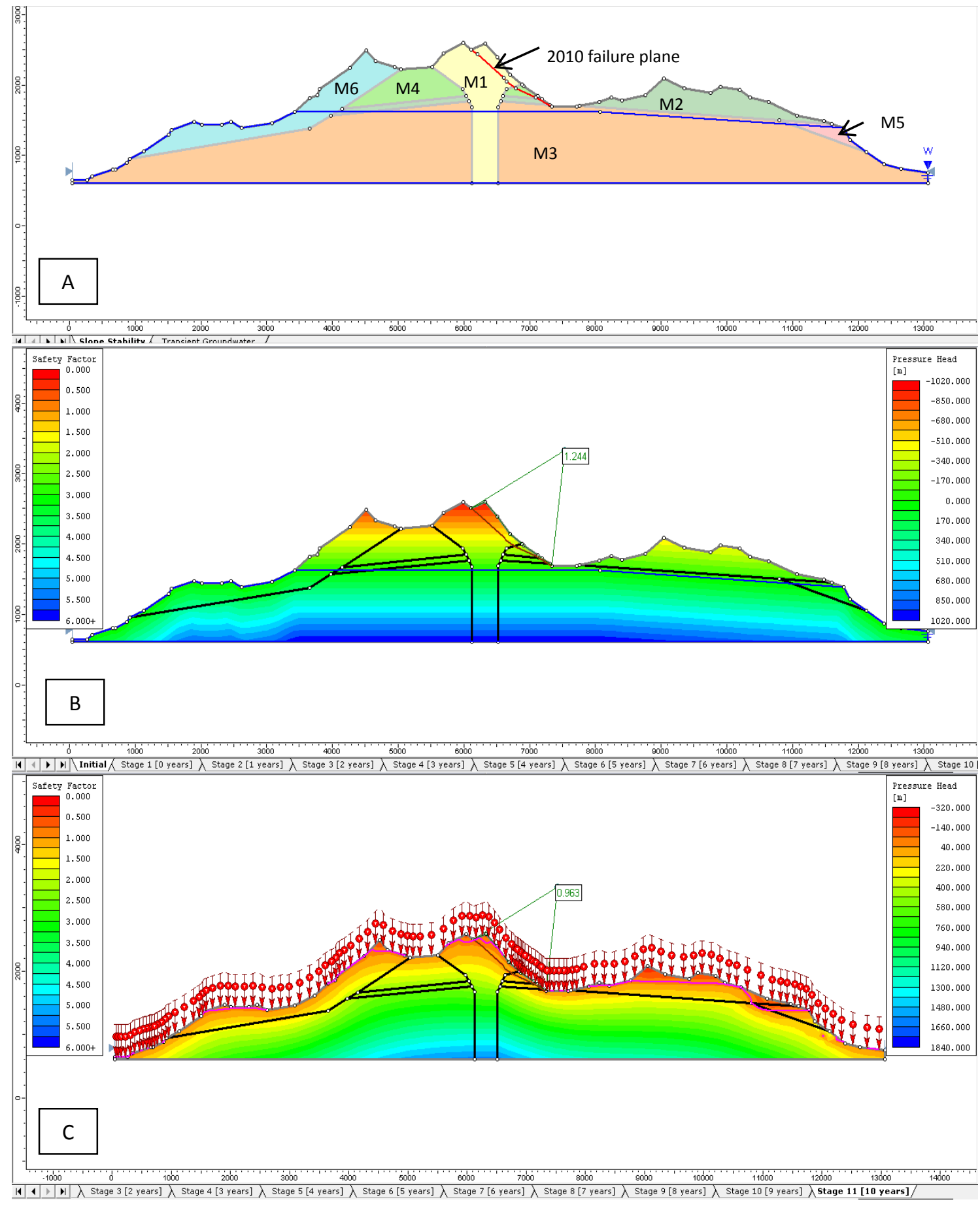

Fig. 22. N-S profile. Slide model and back analysis up to the 2010 failure. A) Model before analysis showing profile and assumed internal structure. Materials and the 2010 failure plane are labelled. B) Initial stage showing FOS of the specified plane before infiltration. This shows that the southern side of Mount Meager was already inherently unstable without water. C) Final stage of analysis representing 2010. Water table is at the surface (pink line) and the FOS has decreased to 0.963 


\subsection{All Failures}

Conditions were applied to all areas along the N-S profile to verify the lowest FOS was at the 2010 failure site. The northern section of the Complex displayed a higher FOS, suggesting the values used were realistic. If the FOS was lower than at the 2010 site, it would suggest this area should have failed instead. At the initial stage, the northern half appears stable with a FOS of 1.4. Again, when infiltration is added the FOS decreases significantly, but remains at 0.994 throughout. This area displays a deep failure surface, which includes a large portion of Plinth and section of Meager Peak. Some stages show a lower FOS of 0.845 for a small area on the northern side of Mount Meager (Fig. 23). The southern section of the profile had an initial FOS of 1.012 and decreased to a minimum of 0.882 with infiltration. All failure planes with a FOS below 1.04 occurred at Mount Meager Peak. Failure planes with a FOS above this also occurred in the southern section of the model, towards Pylon Peak (Fig. 24).

\subsection{After Failure}

'After failure' models, which attempt to predict areas of possible future failures, shows that in the southern half of the profile, all failures below FOS 1.2 occur on the very southern section, and not at Mount Meager Peak. This has important implications for hazard assessment as this area is directly above Meager Creek. Large landslides here could lead to damming of the river and future breach leading to widespread flooding downstream. The lowest FOS is 1.075 (Fig. 25) with a few failure planes with FOS lower than 1.1 and many below 1.2. In the northern half the lowest FOS is 0.998 with many planes having a FOS less than 1.1. These surfaces are all very deep and many include a large section of Mount Meager as well as Plinth (Fig. 26).

The 'after failure' modelling started with a higher water table as seepage could be seen from images taken after the 2010 failure. The lowest FOS values for the northern and southern sections did not change from the initial stage to the last stage, suggesting these areas may be insensitive to the infiltration values provided. Alternatively, as the FOS values are already low, even a small amount of infiltration in a year could raise the water table and render the slope unstable. The last large failure at Plinth occurred at the time of the last volcanic activity, suggesting this area could become more hazardous if volcanism is renewed. 


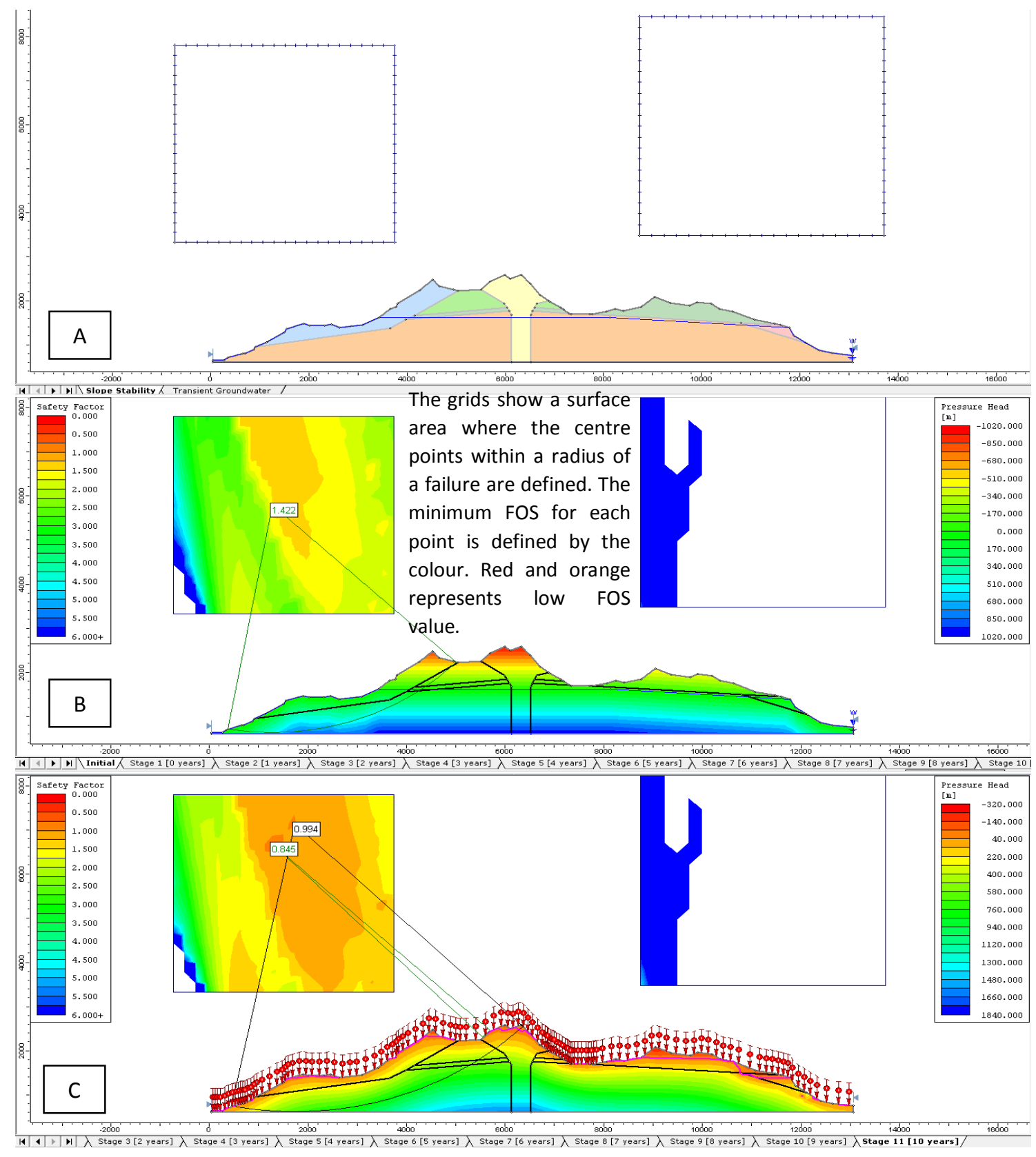

Fig. 23. N-S profile. Slide model and back analysis showing all failure planes below FOS of 1 for the northern side of the section. A) Model before analysis. Grids are for analysis using grid search in each direction. B) Initial stage showing FOS of the weakest plane before infiltration. This shows that the northern side of Mount Meager was moderately stable without water. C) Final stage of analysis representing 2010. Water table is at the surface (pink line) and the lowest FOS has decreased to 0.845 . The deep failure plane shows a FOS of 0.994. The failure plane indicted at Mount Meager (FOS of 0.845 ) may have resulted in a relatively small rock fall onto Capricorn Glacier which would likely have gone unnoticed. The deep failure below Plinth (FOS of 0.994) shows it is at the point of failure. The speed of failure however cannot be determined using Slide. This therefore may indicate slow, progressive movement as seen at various locations around the MMVC. 


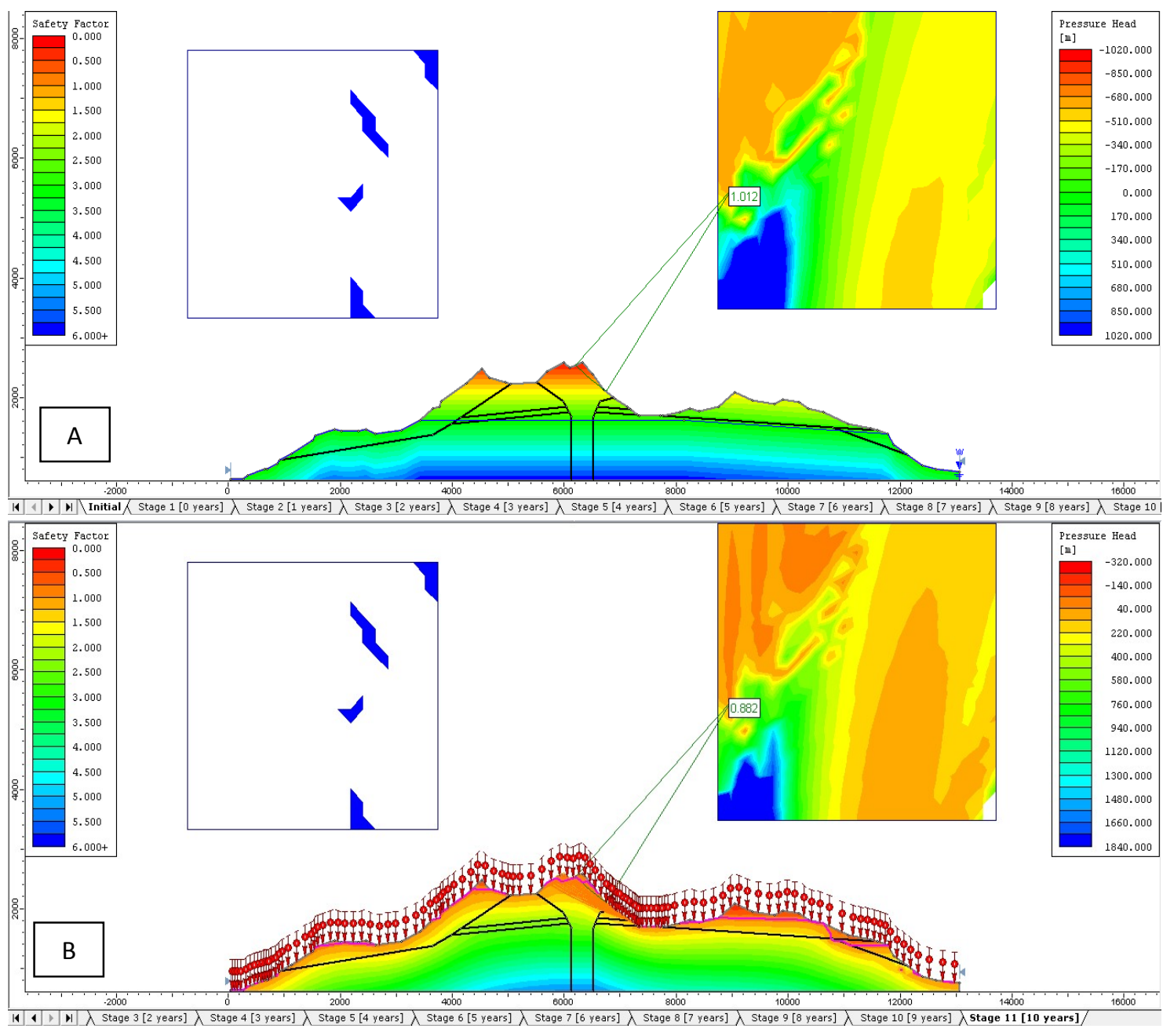

Fig. 24. N-S profile. Slide model and back analysis showing all failure planes below FOS of 1 for the southern side of the section. A) Initial stage showing FOS of the weakest plane before infiltration. This shows that the southern side of Mount Meager was already at the point of failure. B) Final stage of analysis representing 2010. Water table is at the surface (pink line) and the lowest FOS has decreased to 0.882 . All failure planes with a FOS below 1 are located at the peak of Mount Meager where the 2010 failure actually occurred. The grids show a surface area where the centre points within a radius of a failure are defined. The minimum FOS for each point is defined by the colour. Red and orange represents low FOS values 


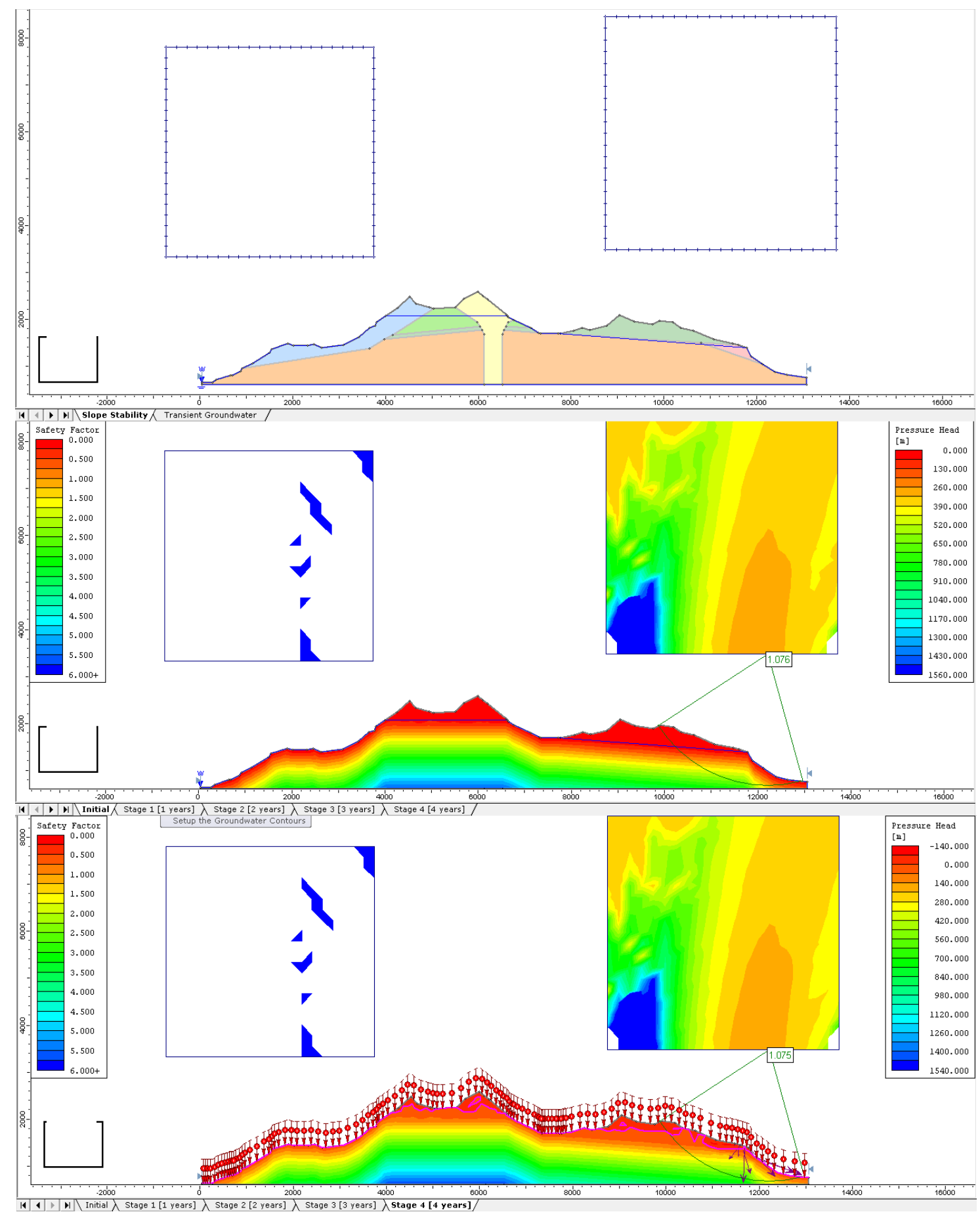

Fig. 25. N-S profile. Slide model for after failure in the southern section. Actual infiltration values were used for stages 1 and 2 (2011 and 2012) and extremes were used for stages 3 and 4 (2013 and 2014). A) Initial model with after failure topography. B) Initial stage showing the lowest FOS before infiltration. C) Final stage after infiltration displaying the lowest FOS. The weakest areas of the southern section are located on the flanks of Pylon. The grids show a surface area where the centre points within a radius of a failure are defined. The minimum FOS for each point is defined by the colour. Red and orange represents low FOS values. 


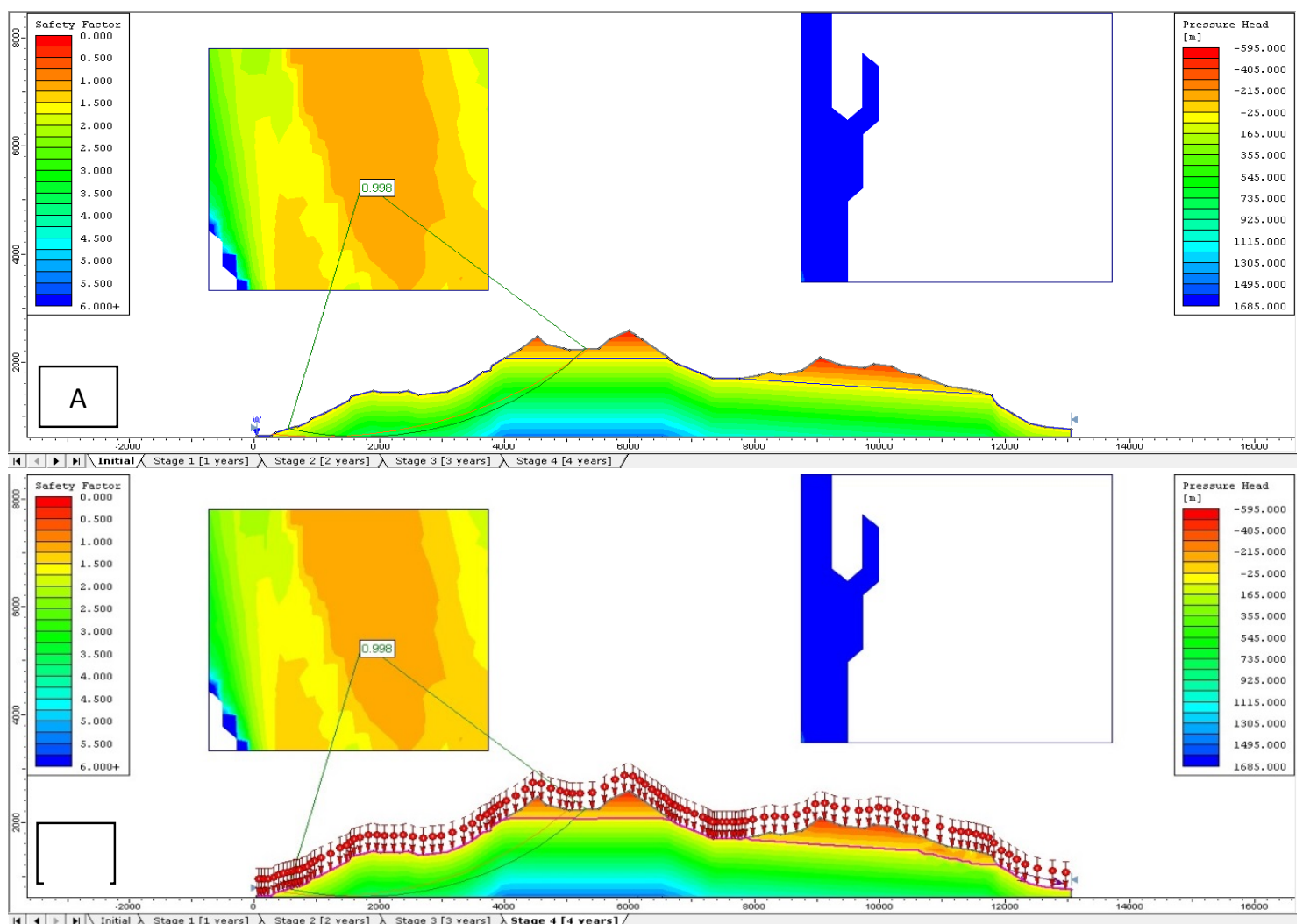

Fig. 26. N-S profile. Slide model for after failure in the northern section. Actual infiltration values were used for stages 1 and 2 (2011 and 2012) and extremes were used for stages 3 and 4 (2013 and 2014). A) Initial stage showing the lowest FOS before infiltration. B) Final stage after infiltration displaying the lowest FOS. The FOS in the northern part of the profile is non-changing, but appears to be at failure. The grids show a surface area where the centre points within a radius of a failure are defined. The minimum FOS for each point is defined by the colour. Red and orange represents low FOS values.

\subsection{South West - North East Profile}

A SW-NE profile through Mount Meager was also modelled testing stability of the eastern flank of Plinth Peak. With failure in the NE direction (Fig. 27), the weakest area at the initial stage (before infiltration) is in the deposits at the bottom of the profile, entering the valley with a FOS of 0.573 . Once infiltration was added, the lowest FOS was 0.722. The FOS was higher after infiltration than in the initial stage, which is contradictory to the normal assumption, and to that shown in the other models. This is because the location of the weakest plane changes from a shallow failure plane to a deep failure plane, showing that infiltration has an effect at depth, reducing the FOS of deep planes. The FOS value, however, is very low suggesting failure. This may indicate that either there is slow, on-going, progressive failure, or no failure is occurring here and the material is stronger than assumed in the models. 


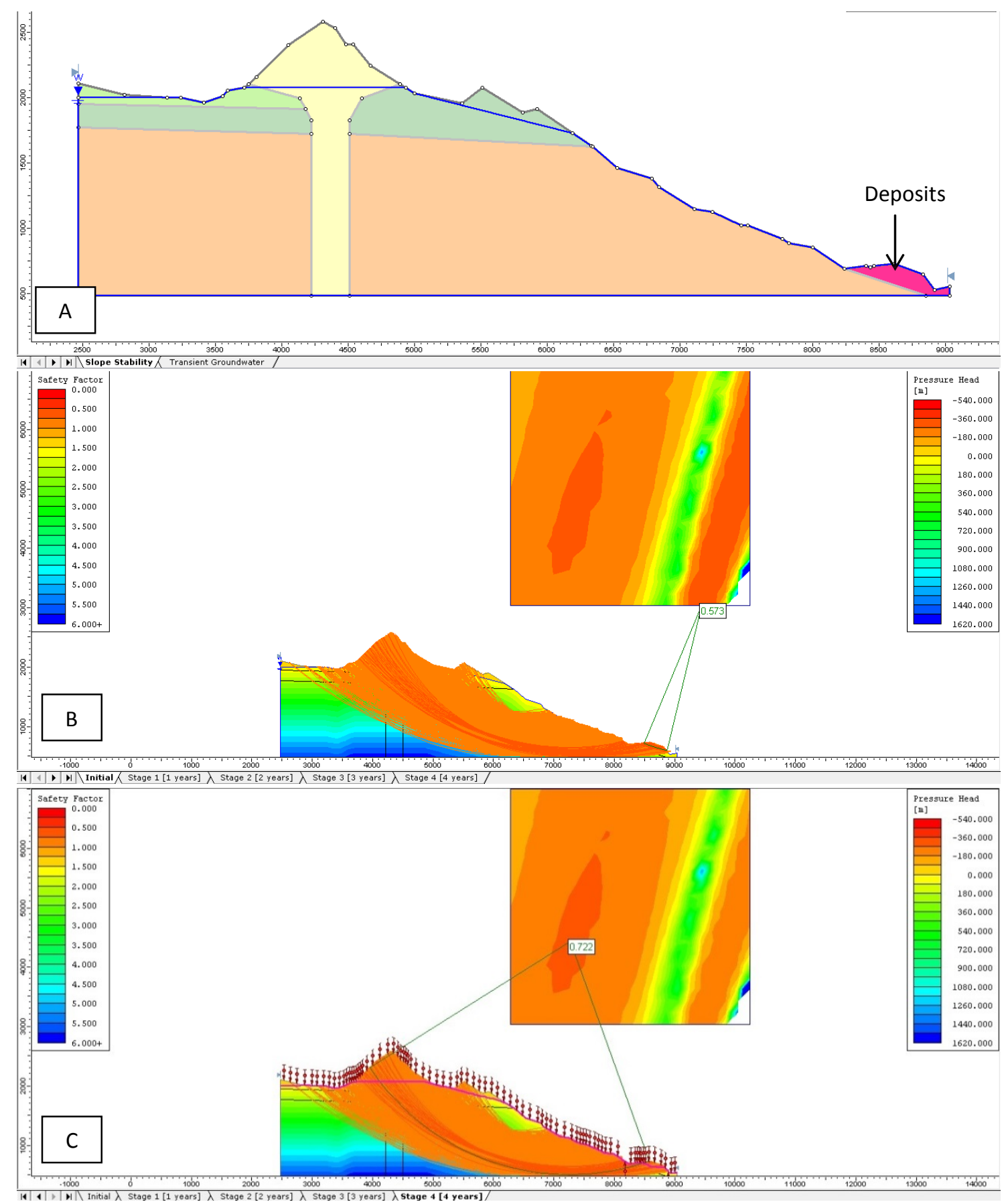

Fig. 27. SW-NE profile. Slide model for after failure infiltration through Mount Meager and the eastern flank of Plinth. Actual infiltration values were used for stages 1 and 2 (2011 and 2012) and extremes were used for stages 3 and 4 (2013 and 2014). A) Initial profile with assumed internal structure. B) Initial stage showing the lowest FOS before infiltration. C) Final stage after infiltration displaying the lowest FOS. The eastern flank of Plinth appears to be at failure along many possible planes. The grids show a surface area where the center points within a radius of a failure are defined. The minimum FOS for each point is defined by the colour. Red and orange represents low FOS values. 
There were many failure planes with a FOS below 1, most being deep failures and including the peak of Mount Meager (Fig. 27). The extreme infiltration values at stages 3 and 4 appear to have no impact on slope stability in this profile. Slope failure of the eastern flank of Plinth would have significant effects on communities downstream as it is situated directly above Lillooet River Valley. Damming and future breach of the dam could cause extensive flooding downstream.

Failure to the SW shows an initial minimum for FOS is 0.912. The FOS increases slightly with each stage, the final stage having a lowest FOS of 0.918. This failure would remove the bulk of Meager Peak (Fig. 28). Failure here would travel down Capricorn Creek and likely dam Meager Creek and possibly Lillooet River.

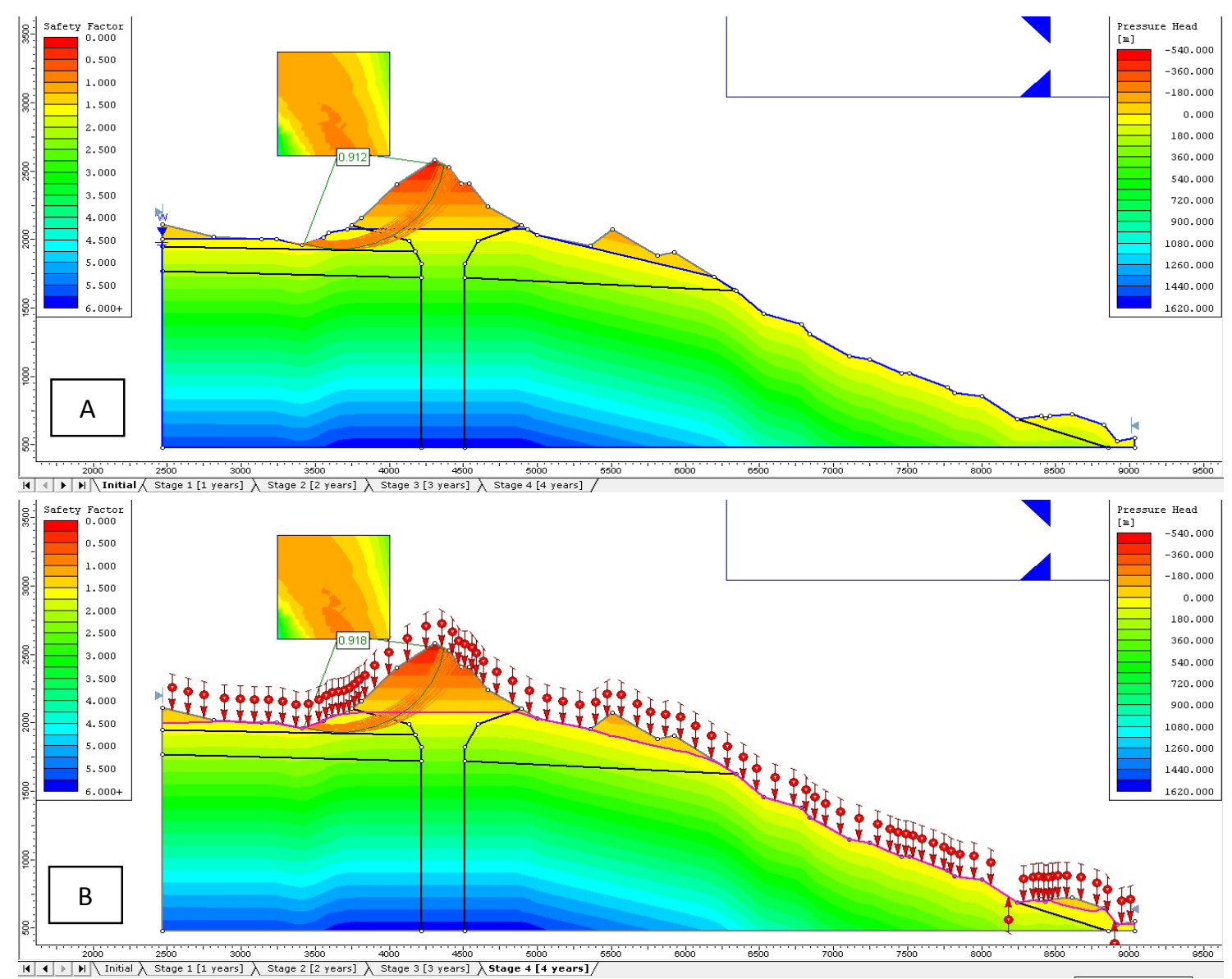

Fig. 28. SW-NE profile. Slide model for after failure infiltration through Mount Meager and the eastern flank of Plinth. Actual infiltration values were used for stages 1 and 2 (2011 and 2012) and extremes were used for stages 3 and 4 (2013 and 2014). A) Initial stage showing the lowest FOS for the south-western face of Mount Meager Peak before infiltration. B) Final stage after infiltration displaying the lowest FOS. The south-west face of Mount Meager appears to be at failure. Material removed here would flow down Capricorn Creek into Meager Creek, likely damming the river. The grids show a surface area where the centre points within a radius of a failure are defined. The minimum FOS for each point is defined by the colour. Red and orange represents low FOS values. 


\subsection{Job Creek}

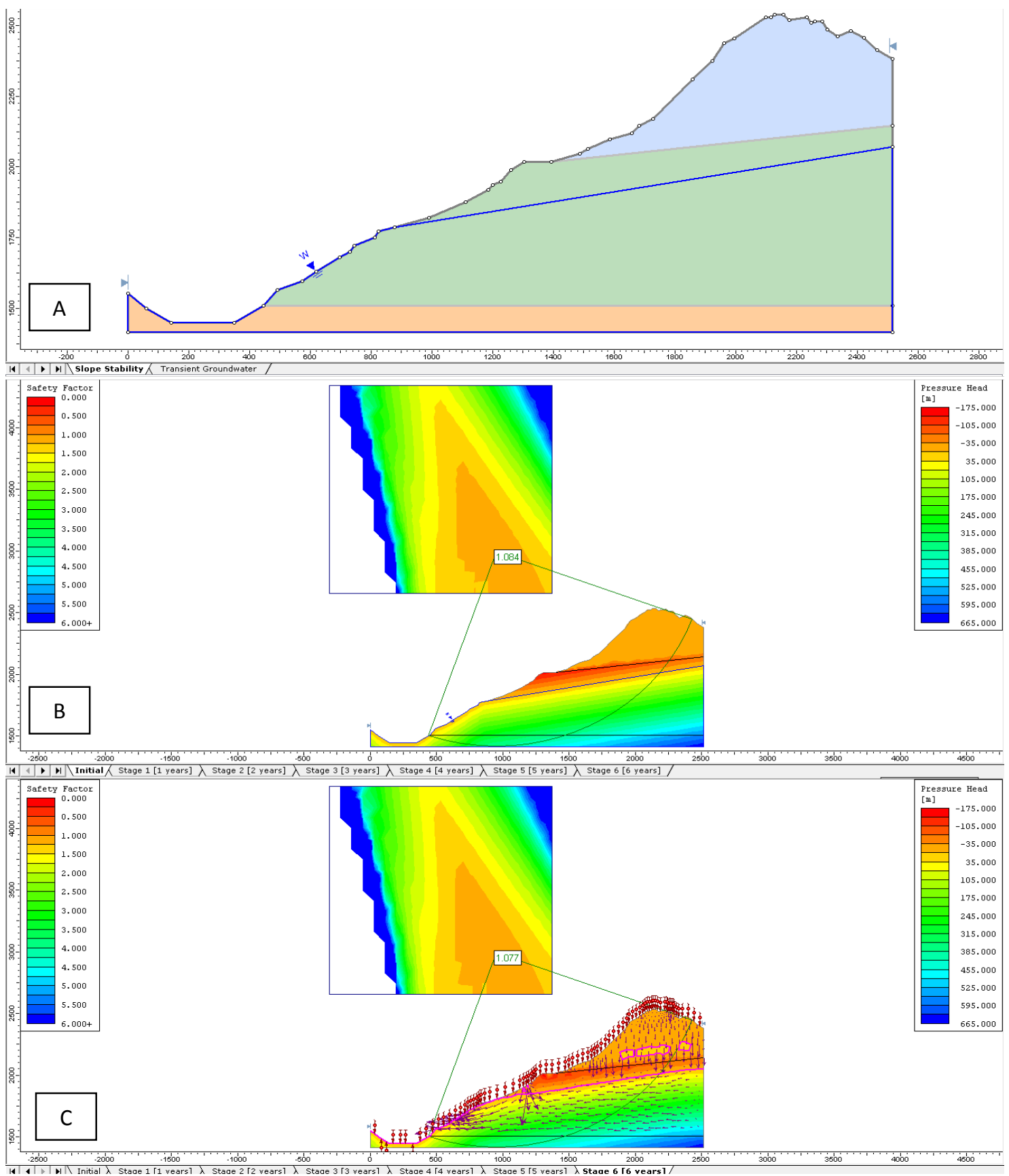

Fig. 29. Job Creek/Plinth profile. Slide model for after failure infiltration for the western flank of Plinth into Job Creek. Actual infiltration values were used for stages 1 and 2 (2011 and 2012), two random, but similar values chosen for the following two stages and extremes for the last two stages. A) Initial profile with assumed internal structure. B) Initial stage showing the lowest FOS before infiltration. C) Final stage after infiltration displaying the lowest FOS. The western flank of Plinth has a FOS indicating instability along a deep failure plane. The grids show a surface area where the centre points within a radius of a failure are defined. The minimum FOS for each point is defined by the colour. Red and orange represents low FOS values. 
Preliminary mapping showed there to be an area of possible instability in Job Creek on the western flank of Plinth. The initial stage shows that this area is already unstable before infiltration is added, having a FOS of 1.084. When infiltration is included the FOS drops to 1.077. At each stage the failure plane is deep, having implications for Lillooet River. The upper boundary of M2 appears slightly impermeable, causing a concentration of water within the upper material (M6). The model shows a large amount of internal flow (Fig. 29).

All scenarios tested to verify parameters showed a gradual decrease in the FOS over time, as opposed to a sudden drop. This suggests the massif is generally weakening with time. Therefore, under current conditions, landslides are becoming more likely. Frequency of failures could therefore be expected to increase.

\subsection{Area and Volume Estimates}

An estimate of the area of material within the failure planes was calculated from the Slide models. As these models are 2-dimensional, Google Earth was used to determine an estimate volume by estimating the width of the surface area likely affected by failures at the possible sites identified. For the $\mathrm{N}-\mathrm{S}$ profile, failure to the south (Pylon) has the capability to generate a landslide of the order of $3 \times 10^{9} \mathrm{~m}^{3}$ and to the north (Plinth) a volume of $4 \times 10^{9} \mathrm{~m}^{3}$. For the SW-NE profile, failure to the north-east (eastern flank of Plinth) has the ability to generate a volume of the order of $5 \times 10^{9} \mathrm{~m}^{3}$, and to the south (Mount Meager) a volume of around $7 \times 10^{7} \mathrm{~m}^{3}$. The western flank of Plinth (Job Creek) could fail with of volume of approximately $1 \times 10^{9}$ $\mathrm{m}^{3}$. These failures are all along deep failure planes.

\subsection{LAHARZ Modelling}

Results from the LAHARZ models showed that a huge volume is needed for a lahar/debris flow to reach the town of Pemberton. A flow of approximately $10^{8}$ $\mathrm{m}^{3}$ would reach the outskirts of the Pemberton area and cause disruption to roads. It would take a flow with a volume of $3 \times 10^{8} \mathrm{~m}^{3}$ to reach the main part of the town and disrupt the railway. Most, if not all, of Pemberton town would be covered by a flow with a volume of $3.5 \times 10^{8} \mathrm{~m}^{3}$. With a flow of $5 \times 10^{8} \mathrm{~m}^{3}$, the whole valley would be inundated with material (Fig. 30). Volumes of this size can only be generated by large, deep-seated landslides and/or by the creation and failure of significantly large dams.

Slide modelling shows that failures of the flanks of Pylon Peak, the northern and eastern flanks of Plinth, and the western flank of Plinth (Job Creek), have sufficiently 
deep failure planes that could generate volumes of this size and greater. Mapping and literature research also suggests there are many other sites around the MMVC where deep failure could occur, such as at Affliction Creek and Devastation Creek.

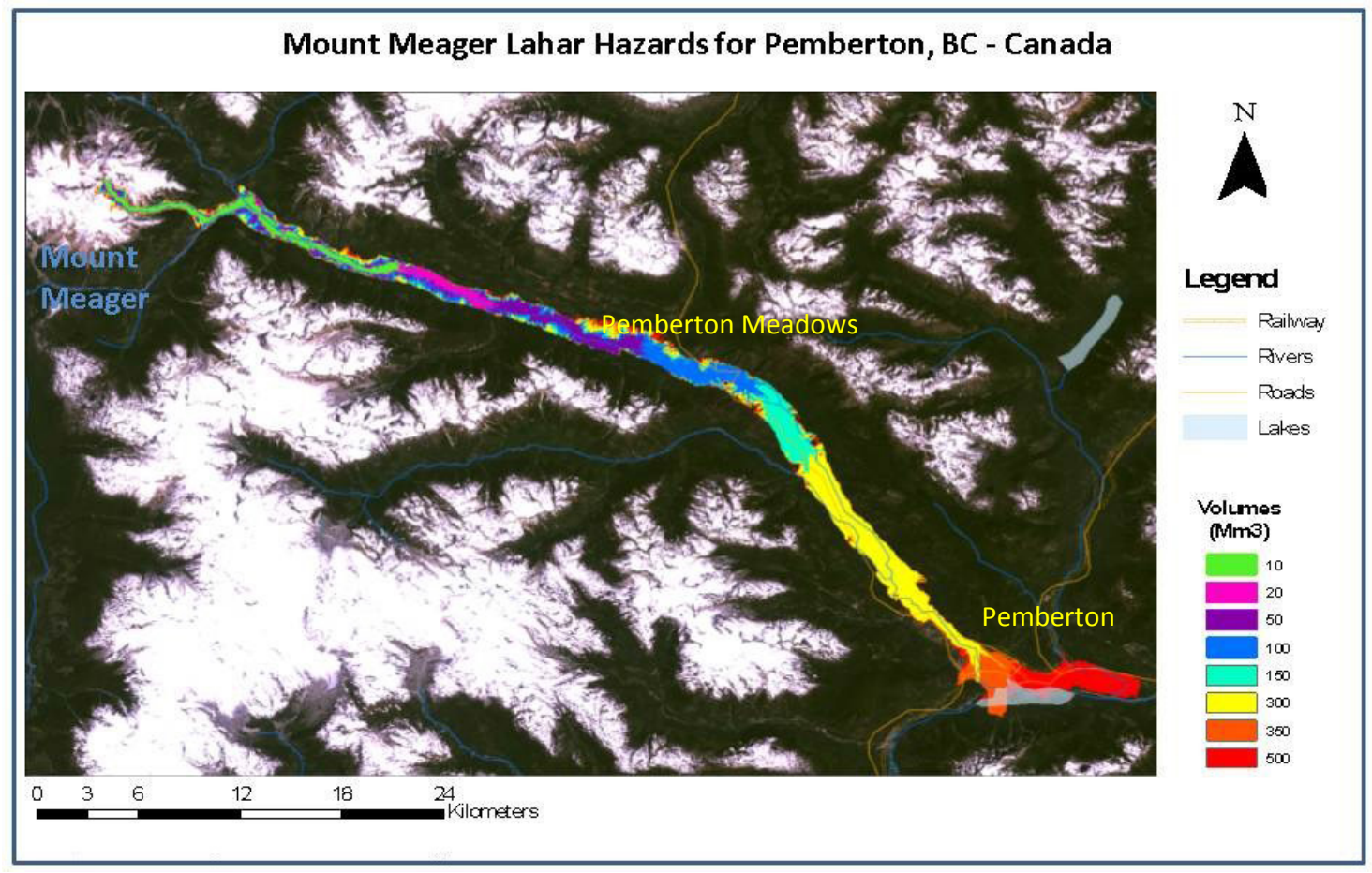

Fig. 30. Hazard inundation map, using LAHARZ and ArcGIS, showing volumes and extent of various debris flow simulations originating from Mount Meager in Capricorn Creek. Flows overlain on a Natural Colour Landsat TM image (25/07/2010) (www.earthexplorer.usgs.gov). Infrastructure data from www.geocomm.com.

\section{Analysis}

\subsection{Hydrology}

In all N-S models the water table rose to the surface once infiltration started, regardless of the initial position. This indicates that, if the model parameters are correct, the water table would always be at high elevation within the Complex as opposed to intermediate elevation as previously thought. There is also a fairly continuous supply of water, either through rainfall or snow-melt, so the water table would not drop to intermediate level. At the initial stages, the lowest FOS was higher than those when infiltration was included. This confirms that the water infiltrated increases instability. It also shows that even without water the slopes are still unstable. 


\subsection{Factor of Safety}

All models showed a gradual decrease in the FOS with each stage. As there were no sudden drops in stability it can be assumed that no sudden or large changes are needed for failure to occur, as small changes can be sufficient to trigger the final failure. So while extremes, such as heavy rainfall or warm months, may be more likely to trigger landslides, the intervening periods of 'normality' must also be considered hazardous.

Using imagery from Google Earth, it can be seen that there is a small bulge and cliff on the northern side of Mount Meager. The small area of failure (FOS of 0.845), modelled here, is considered to be at failure. It is also possible that this section has already failed onto the glacier unnoticed.

When testing for all failure surfaces, before the 2010 failure, the weakest place was shown to be the south side of the peak of Mount Meager. This can be assumed to be accurate as the failed surface was one of the many possible planes displayed. This can therefore also act as verification for the relative parameter values as the lowest FOS, hence weakest area, was where failure actually occurred.

\subsection{South West - North East Profile}

The SW-NE profile shows that the south-west face of Mount Meager is unstable. If failure occurs here the material will flow down Capricorn Creek, into Meager Creek and possibly into Lillooet River. This could be a similar event to the 2010 failure of Mount Meager, leading to damming of the rivers and a later breach of the debris dam. The eastern flank of Plinth, with failure in a north-eastern direction, has a low FOS indicating it is at the point of failure. These failure planes are deep, and if a landslide occurred in this location a huge bulk of Plinth would be removed damming the Lillooet River and causing a risk of flooding downstream, if suddenly breached. A greater hazard, if failure occurred here, would be the possibility of the triggering of an explosive eruption. The amount of material that could potentially be removed would cause unloading and depressurisation of the magma chamber below, which may in turn trigger explosive activity.

\subsection{Job Creek}

Slide analysis of Job Creek indicates the western flank of Plinth is unstable. This, according to literature, is one of the locations where future failure is expected to occur. The topographic profile shows there is a flat part mid-slope. This, combined with the deep failure planes displayed, suggests this area may be undergoing 
progressive slope movement of the sackung type, similar to Affliction Creek. If this is the case, the flat area may be an antithetic fault. This however, is difficult to confirm using Google Earth, as the area is snow covered, hence underlying details cannot be observed in images.

\subsection{Modelling Extremes}

When modelling future possibilities, extreme infiltration showed no difference from average values. This strengthens the argument above that small changes are sufficient to trigger failure, and extreme changes are not essential. Although there is correlation between extreme conditions and chances of failure, there are many landslides that do not correlate with such events.

\subsection{The Effect of Snow Coverage}

The Slide models show annual changes and not seasonal changes, however literature on historical failures shows that most landslides occur during the summer months. This correlates with higher temperatures and greater rainfall (as opposed to snowfall) and snow-melt, leading to higher infiltration. Satellite images obtained from the USGS database display the seasonal variation in snow coverage. When mapped using ArcGIS, a difference in the area of snow coverage between July 2010 and April 2011 was approximately $27.5 \mathrm{~km}^{2}$ showing a large amount of melting occurs during the summer. Locally, the areas where snow and ice cover retreats/melts the most are at sites where large landslides are commonly known to recur.

To avoid creating greater uncertainty and adding complexities to the models, permafrost layers and melt were not taken into consideration for slope stability modelling. However, permafrost is believed to act as an impermeable layer, and is undergoing considerable degrading due to the warming climate, hence adding to destabilising slopes (Geertsema et al., 2006; 2010; Clague, 2013).

\subsection{Model Assumptions and Validity}

Many assumptions were made for the models. Exact rock parameters were unknown, so guidance was taken from images of the volcanic Complex and Rocscience's RocData program. The internal structure of the Complex is unknown. The exact position of the water table is also unknown, and few studies have been done to test hydraulic properties of the materials composing the MMVC, therefore large assumptions are made here also. Most properties were tried and tested in the back analysis using the 2010 failure data. The accuracy of annual infiltration values 
relies on having an accurate initial value of the average infiltration. There is more precipitation at high elevation, but as there is no recording equipment at these locations, precipitation, and therefore the average, is assumed, leading to a possible under- or over-estimation. Precipitation combines rainfall and snowfall, so infiltration from snow-melt is included in the overall infiltration and not considered separately. As mentioned previously, there is a lack of data on the hydrology of the MMVC, hence internal flow movement is unknown. Any effect the glacier has on internal flow is therefore not considered in the models. It should also be noted that the Slide models are 2-D, so do not take into consideration 3- D effects, such as buttressing and snow loading, which could increase the Factor of Safety. There may also be strong internal compressive stresses holding the massif together, allowing only superficial failures to occur and preventing large, deep failures from becoming more frequent events (van Wyk de Vries \& Matela, 1998).

\subsection{Future Failure}

The N-S profile section cuts through the side of a cirque between Angel Creek and Pylon Creek. The forward modelling results indicate this southern section is unstable, having a FOS of just above 1 . This is an area which has previously been identified by Holm et al. (2004) as a probable location for future failure. They state that there are Little Ice Age (LIA) end moraines in Angel Creek which act as catchments for debris flows in the upper area of the cirque. Debris flow activity may increase sharply in the lower part of the creek when the basin reaches its storage capacity.

\subsection{Volumes}

The estimated volumes that can still be generated at the MMVC could be greater than $10^{9} \mathrm{~m}^{3}$, the largest originating from the northern and eastern flanks of Plinth Peak. These volumes do not account for any entrainment of water and material after detachment, so volumes of the debris flows would likely be larger. According to the LAHARZ simulations and hazard map, the Lillooet River Valley and town of Pemberton would be completely inundated with material if a deep failure occurred in locations modelled in the Slide profiles. These possible failures appear to be larger than any previous events at the MMVC.

\subsection{Technical Problems}

During modelling, various technical problems were encountered. A small range of hydraulic conductivity values caused errors in the results, mainly affecting the pore pressures. Issues in the coding occasionally caused the water table to disappear. Groundwater analysis could be computed separately, but occasionally 
displayed some errors in finding groundwater data when computing the slope stability. It would appear that infiltration caused most of the problems. Solving these technical issues, and making changes to correct for them, was a time consuming process and required help from Rocscience directly. Some of the problems were not fully resolved however changes were made to work around them. Issues may have arisen due to the large scale of the models analysed. Slide is usually used for much smaller sections than those for this project.

\section{Discussion}

\subsection{Future Failure}

As most of the MMVC is underlain by altered and highly weathered volcanic rock, it can be expected that more large landslides will occur in the future (Friele \& Clague, 2004). There is likely to be high frequency activity at Capricorn Creek and Devastation Creek due to the abundance of readily mobilised material available. These are just two of the many areas where poorly consolidated material in the Complex has been uncovered and de-buttressed as a result of glacial retreat (Bovis \& Jakob, 2000). Angel Creek may also experience increased activity as the LIA end moraines, which act as catchments for debris flows in the basin, reach and exceed their storage capacity (Holm et al., 2004).

Preliminary mapping shows there are areas which appear to be unstable and displaying features associated with instability, such as sackungs and fractures. The main sites of potential failure seen when mapping are consistent with those identified by Friele et al. (2008); Devastation Creek, East Job Creek and the flanks of the Devastator and Pylon Peak. Friele et al. (2008) state that the potential failure area at Devastation Creek is ten times larger than the 1975 failure and could generate a volume on the order of $10^{8} \mathrm{~m}^{3}$. According to the LAHARZ results, this would reach the outskirts of the Pemberton area and cause disruption to transport. Partial collapses could have volumes around $10^{6}-10^{8} \mathrm{~m}^{3}$. Instability on the southern flanks around Pylon Peak is confirmed in the $\mathrm{N}$-S profile of the Slide models, with a calculated FOS little over 1.

Large scale deglaciation can cause unloading and depressurisation in volcanic systems leading to a risk of triggering an explosive eruption (Clague, 2013). The Slide models show some of the possible failure planes to be deep, which could remove approximately $5 \times 10^{9} \mathrm{~m}^{3}$ of the Complex material. As the MMVC is classified as potentially active, this could be a realistic hazard for this region. The 
occurrence of small, frequent earthquakes beneath the Meager Massif indicates shallow magmatic activity, supporting the possibility of renewed volcanism in the future (Friele et al., 2008). Earthquakes at the MMVC are one of the triggering mechanisms for slope failures (Simpson et al., 2006). Many landslides at the MMVC have caused damming of rivers. A large landslide could create a significantly sizeable dam, which could cause widespread flooding downstream upon failing. According to the Slide models this is a realistic possibility at Plinth, with both the eastern and western flanks displaying deep failure planes. The valley below the eastern flank of Plinth is where the deposits from the last volcanic eruption of the MMVC are located.

\subsection{Climate Change}

When discussing landslides in British Columbia the main triggers associated with these failures are earthquakes and climate. Climate refers to meteorological conditions, intense rainfall and rapid snowmelt, long-term climate trends, frost wedging, and thawing permafrost (Geertsema et al., 2010). Geertsema et al. (2006) suggest there is a link between climate change and the increase in occurrence of landslides in northern BC. Landslides in mountainous regions may be especially responsive to any increase in temperature (Geertsema et al., 2010). Geertsema et al. (2006) show there is a general positive correlation between years of high temperatures and rainfall with landslide occurrence. This is supported by Jakob \& Lambert (2009), who have found that climate models predict an increase in rainfall within the $21^{\text {st }}$ Century, and therefore an increase in the frequency of landslide occurrence. They state that most landslides in coastal BC are triggered by hydroclimatic events, mainly prolonged rainfall followed by, or associated with, a period of intense rainfall. However, they have found there to be no persistent trend in rainfall intensity over the past four decades. In BC, shallow failures are typically associated with periods of heavy rainfall or rapid snowmelt. However, due to a sparse climatological network in valley bottoms, the data on amount of rainfall occurring is not representative of the weather at landslide locations. Large deep failures usually have a delayed response to precipitation, suggesting long term climate trends influence deep landslides. Rapid or delayed melting of above average snowfall can increase landslide activity. Melt water infiltrates cracks and fractures causing joint expansion through freeze-thaw processes (Geertsema et al., 2010).

Hewitt et al., (2008) support the claim that climate events can trigger landslides. Various scenarios of climate change suggest the winters in the Coast Mountains region will become wetter and warmer, experiencing more intense rainfall later 
during this century (Friele et al., 2008; Jakob \& Lambert, 2009). All large historic landslides within the Meager Creek watershed have occurred in summer, either during or following warm spells (Friele \& Clague, 2004; Huggel et al., 2012), leading to greater snow and ice melt, likely triggering failure due to the increase in pore pressures (Friele \& Clague, 2004). Geertsema et al. (2010) state that global climate change could be affecting landslide rates in mountain ranges around the world. In the Alps and BC, permafrost may be degrading due to the warmer climate, decreasing slope stability (Geertsema et al., 2006; 2010).

\subsection{Glacial Hazard}

Glaciation and deglaciation are key factors affecting the distribution, magnitude, frequency and behaviour of rock avalanches (Hewitt et al. 2008). The Coast Mountains of $B C$ are one of the places that have experienced the greatest ice loss

over the $20^{\text {th }}$ Century. Glacial thinning and retreat appears to be responsible for many rock failures in mountain regions during this time (Clague, 2013). This is ultimately dependent on climate change (Hewitt et al., 2008). Post-LIA retreat is one of many factors influencing landslide activity in the Coast Mountains of BC. The spatial frequency of surficial failures within the Neoglacial limit and the occurrence of rock falls along glacial trimlines have increased, hence the chances of large catastrophic failures in weak rocks have also increased. Many landslides at the MMVC have been triggered by glacial de-buttressing, such as Devastation Creek (1975) and Capricorn Creek (1998) (Holm et al., 2004). Capricorn Basin and Devastation Basin show similar patterns of catastrophic failure as a result of involving slopes which have undergone de-buttressing (Bovis \& Jakob, 2000).

Temperatures in glaciated mountains are usually below freezing; however, warm periods cause a rapid rise in temperature hence melting of snow and ice. Meltwater then infiltrates cracks and fractures increasing water pressure and producing extensional forces on already weak rock masses. The thawing of permafrost is also possibly related to slope failure as permafrost melt infiltrates fractures at high elevations (Clague, 2013). Holm et al. (2004) found that basins within the MMVC generally displayed greater slope undercutting along Neoglacial trimlines than granitic basins, showing that glacial retreat weakened and destabilised slopes more at this Complex. The frequency and magnitude of landslides is therefore substantially higher in and around the MMVC than other areas. All basins at the MMVC studied by Holm et al. (2004) exhibited evidence of non-catastrophic gravitational slope deformation. Deep- seated slope movement or large scale catastrophic failure associated with Neoglacial retreat, is more commonly observed in weak rocks such 
as the quaternary volcanics of the MMVC. All large failures of these rocks occur within areas of previous gravitational slope deformation and directly above slopes which have been undercut by Neoglacial scour.

Preliminary mapping of the MMVC shows that the main areas of instability are located at in valleys which have undergone the most extensive glacial retreat, such as Affliction Creek and Devastation Creek.

Many slope failures at MMVC originate as rock avalanches and transform into debris flows. This style of failure is rare and does not fit with conventional classification. Catastrophic Glacial Multi-Phase Mass movement (CGMM) is a new term created to describe events of this kind. Failure usually initiates as a rock or ice avalanche, which transforms into an ultra-high speed flow (>30 m/s), then into a debris flow. A key feature of these phenomena is that transformation from rock avalanche to debris flow is a result of fluidisation. The Devastation Creek failure in 1975 is an example of a CGMM event (Petrakov et al., 2008). Volcanic rock was displaced beneath the glacial bed leading to a downstream advance of an approximately $2.5 \times 10^{6} \mathrm{~m}^{3}$ section of the glacier snout (Mokievsky-Zubok, 1977; Petrakov et al., 2008). The material became saturated in water and ice substantially increasing its volume becoming a debris flow. The trigger for the slide was mainly due to the action of melt water from the glacier. It is suggested that prior to the final trigger, the main mass needs to be in a state of preparedness for catastrophic failure. CGMM events repeat in the same area, but with no clear return period. Evidence for this is that there have been three catastrophic events documented at Devastation Glacier during the $20^{\text {th }}$ century (Petrakov et al. 2008).

\subsection{Hydrology}

Groundwater dynamics and position of the water table within a volcanic edifice have significant implications on volcanic hazards with slope failure, lahar generation and phreatic eruptions strongly influenced by water table elevation (Hurwitz et al., 2003). This is supported by the Slide models in Section 7 which show the massif to have a slightly higher FOS at the initial stage of each location before infiltration is added and when the water table is positioned at a lower elevation. In fully saturated material the fluid pressure is positive reducing the effective stress, thus increasing the likelihood of slope failure. A deep water table would therefore mean there cannot be sufficiently high enough fluid pressures to enhance potential for failure above. The main problem however, is that knowledge of water table positions and geometry is limited as little direct evidence can be obtained from 
active volcanic cones. This is due to the difficulty of having drill holes on or within the vicinity of volcanic summits (Hurwitz et al., 2003). Also, the MMVC is glaciated mountain terrain with numerous geologic units and hydraulic properties so is one of the most complex hydrologic landscape to describe (Winter, 2001).

Results from simulations indicates the permeability structure of the edifice and underlying material has dominant control on the elevation of the water table and distribution of pressures. Previous numerical simulations of heat transport and groundwater flow of Quaternary volcanics in the Cascades determined permeabilities on the order of $10^{-14} \mathrm{~m}^{2}$. However, the permeability structure is subject to the greatest uncertainty.

Variations in precipitation recharge rate also have a large impact on water table elevation. Extensive ice caps could restrict recharge at the summit and on the upper flanks. The water table may be relatively deep with low recharge from precipitation and high permeability, and saturated if high recharge and low permeability. Along sloping surfaces, seepage usually occurs in the lower sections of the slope, and the upper sections receive precipitation recharge. However, seeping areas can become non- seeping if the seepage rate becomes positive, and non-seeping areas can become seeping, if the pressure rises above that of the atmosphere.

These parameters do not stay constant over geologic time as the edifice evolves. There may be positive feedback between the water table elevation and hydrothermal alteration as alteration tends to decrease mechanical strength and permeability (Hurwitz et al., 2003).

\subsection{LAHARZ}

Research by Simpson et al. (2006) has found three large volume debris flow deposits in the Lillooet River Valley. According to this research the town of Pemberton is built on top of lahar deposits from one of these huge volume events. This is evidence that failures of this size are possible and, although rare events, plans for mitigation and evacuation should be in place in preparation for one of these large scale flows. The three large volume debris flows found in the Lillooet River Valley all had volumes above $10^{8} \mathrm{~m}^{3}$. The oldest debris flow unit was deposited around 6,250 years BP with a volume of $10^{8}-10^{9} \mathrm{~m}^{3}$. The middle unit from 4,400 years BP had a volume of $2 \times 10^{8} \mathrm{~m}^{3}$ and the youngest of the flows, deposited around 2,600 years BP had a volume of $10^{8}-10^{9} \mathrm{~m}^{3}$. These volumes are likely to 
be the minimum due to erosion and burial within the valley (Friele et al., 2008). Failures of this size appear to be infrequent events, as suggested by the dates of these flows, however they should be considered in building and development regulations. Events on a smaller scale happen more frequently, as mentioned previously.

According to a risk assessment by Friele et al. (2008), the residents of the Pemberton settlements are vulnerable to debris flows of between $10^{7}-10^{8} \mathrm{~m}^{3}$, which could reach the upstream limits of the settlements areas and debris flows of $10^{8}-10^{9} \mathrm{~m}^{3}$, which would completely inundate the whole Lillooet River Valley up to $75 \mathrm{~km}$ from Mount Meager volcano. As this region of BC does not have any risk standards in place, Friele et al. (2008) used international standards from Australia, Hong Kong and the United Kingdom to determine risk to the residents of the areas in question. They concluded that individuals in the Pemberton areas are 5.4 times more at risk than is acceptable.

Results modelled in LAHARZ by Simpson et al. (2006) show that a lahar with a volume of $10^{8} \mathrm{~m}^{3}$ reaches the same extent as a lahar with a volume of $5 \times 10^{7} \mathrm{~m}^{3}$ according to models done for this study. This flow may possibly extend as far as Pemberton Meadows ( $\sim 55 \mathrm{~km}$ downstream of Mount Meager). According to Simpson et al. (2006) a volume of $10^{9} \mathrm{~m}^{3}$ would be required to inundate the valley and town of Pemberton; however according to this study, a volume of $5 \times 10^{8} \mathrm{~m}^{3}$ would be sufficient. Models from this study therefore suggest a smaller volume is required to reach settlements and cause inundation of the valley than previous studies have found. This therefore implies the risk to Pemberton and surrounding settlements may be higher than first calculated.

This difference between the results however, is likely due to an alternative origin for the initial LAHARZ modelling chosen by Simpson et al. (2006). Their map displaying the distal flow simulations originates in Job Creek on the northern side of the MMVC, so having a greater distance from Pemberton than models in this study. However, they state that distal inundation zones are similar to those of models originating at other Creeks around the Complex. The DEMs used in this study may be different to those used by Simpson et al. (2006) as the date of acquisition for the DEMs would be in line with the date of the research undertaken. Those used for this study are therefore likely to be more recent, hence having a slightly differing topography. Various other factors also contribute to the extent a flow will travel, so these need to be considered further when producing an accurate hazard map.

As mentioned previously, mitigation plans need to be developed in preparation 
for debris flows of this scale. Even though they are infrequent events, the Slide models show that the MMVC still has the capacity to deliver flows of this magnitude. If not already in place, early warning systems should be implemented due to the knowledge that most landslides in the MMVC occur without warning. Flows of this size would likely overcome many mitigation strategies in the valley so it would be important to have a good evacuation plan in place.

\subsection{Overview of Similar Failures in British Columbia}

\section{i. Southern British Columbia}

The following four examples are of areas in southern BC, near the MMVC, where previous failures and movements have been documented.

Mount Cayley is a stratovolcano and one of the three volcanic centres of the Garibaldi Volcanic Belt, along with Mount Meager and Mount Garibaldi (Stewart et al., 2003). Several large landslides have originated from the western flank of Cayley during historic time with frequent occurrence of smaller debris flows which disrupted access to the area (Friele \& Clague, 2004). Many of these landslides have blocked Squamish River and caused flooding (Hickson et al., 1999; Friele \& Clague, 2004).

The Cheam landslide, which occurred approximately 5,000 years ago, is one of the largest events in British Columbia with a volume of $17 \times 10^{7} \mathrm{~m}^{3}$ (Hewitt et al., 2008).

Deformation through toppling movements has been documented at Mount Currie, which is located close to the town of Pemberton (Bovis \& Evans, 1996).

The Hope Slide, a debris avalanche event, of 1965, was comparable in size to the 2010 failure at Mount Meager (Guthrie et al., 2012). Prior to failure, there had been long term deformation, where sackungs and linears had been observed (Bovis \& Evans, 1996; Hewitt et al., 2008), suggesting a relationship between deformation on a long time scale and slope failure. The 1965 landslide entrained water and generated a debris flow in the valley (Hewitt et al., 2008).

\section{ii. Northern British Columbia}

Similarly, several large landslides have been documented in northern BC. The following are just six examples.

The Muskwa flow of 1979 was classified as a rock slump-earth flow, involving both 
rock and soil. It was a large failure with a volume of $15 \times 10^{6} \mathrm{~m}^{3}$, which created a dam in Muskwa River. The dam was later partially breached.

The Mink Creek flow occurred in December 1993 or January 1994, with failure of sediments and soils. The volume of the flow was $2.5 \times 10^{6} \mathrm{~m}^{3}$ and also dammed the river. This event was preceded by a decade of warmer and wetter conditions.

The Zymoetz failure of June 2002 was a rock slide-debris flow with a volume of $1.6 \mathrm{x}$ $10^{6} \mathrm{~m}^{3}$, which caused damming of the Zymoetz River. This led to flooding upstream upon failure. This event ruptured the gas line, disrupting service to the surrounding areas.

The Harold Price rock slide-debris flow also occurred in June 2002. The volume of failed material was equal to that of the Zymoetz failure. The degrading of permafrost is considered likely to have played a role in this failure.

Pink Mountain also failed in June 2002 with a volume of $1 \times 10^{6} \mathrm{~m}^{3}$. This event was classified as a rock slide-debris avalanche. Failure occurred in an area of mountain top deformation and transformed into a debris avalanche.

The McCauley Mountain rock slide in southern BC occurred around the same time as the three above. All June 2002 failures are believed to be associated with the delayed melting of an above-normal snow-pack (Geertsema et al., 2006).

\subsection{Future Work}

There are many assumptions in the modelling causing uncertainties and possible inaccuracies in the results. Materials composing the MMVC need to be tested and determined in order to constrain the range of values used in the models. This would involve undertaking some intensive, difficult and dangerous fieldwork, which was not done for this study. Infiltration is an important factor affecting slope stability, hence precipitation could be better monitored at high elevation sites around the Complex allowing for more accurate modelling of infiltration. Further modelling could also be undertaken to assess the impact of infiltration over shorter time scales as opposed to annual variations. Reliable values for rock and hydraulic properties can then be used to develop a threshold for materials composing the MMVC. The hydrology of the area is complex and largely unknown, however the location of the water table has significant impacts on volcanic hazards. This means the hydrology of the Complex needs to be refined in order to obtain more accurate and reliable analyses on slope stability. The position of permafrost layers 
and thawing requires greater focus in order to refine the details of the modelling.

\section{Conclusions}

Regional tectonics, seismicity, geological structure, lithology, relief and climate are main factors which work together in preconditioning a slope for failure and in determining behaviour and activity of landslides (Hewitt et al., 2008).

According to the hazard map produced by simulations using LAHARZ, it would take a large volume debris flow to reach the town of Pemberton, $65 \mathrm{~km}$ from Mount Meager. However, the MMVC has the potential to generate flows of this size as both Slide modelling and previous studies have found. Five main areas can be identified as currently having a greater likelihood of failure; West Devastation Creek, the southern flank of Pylon Peak, the bulge at Job Creek, Affliction Creek and the eastern flank of Plinth Peak. The first four of these locations have clearly visible unstable features and the fifth is a steep cliff, which failed during the last volcanic eruption.

The warming climate and consequent glacial retreat has exposed many areas of poorly consolidated material and caused the de-buttressing of slopes around the MMVC. Many historic landslides have closely followed periods of above average temperatures and rainfall. However, annual infiltration modelled in Slide showed there were small, gradual decreases in the FOS with each stage, as opposed to a sudden drop resulting in failure. This indicates that all conditions should be viewed as hazardous to stability and that minor changes could trigger failure. The massif appears to be unstable, even without the presence of water, also supporting that minor changes could lead to failure.

The Slide models indicate that the MMVC still has the capability for generating large volume debris flows. If failure occurred along a deep failure plane, volumes greater than $10^{8} \mathrm{~m}^{3}$ could be delivered to Lillooet River, which would inundate the entire valley, including the town of Pemberton. Friele et al., (2008) believe a

failure of the order of $10^{8} \mathrm{~m}^{3}$ is both possible and likely to occur at Devastation Creek. These events are infrequent but can occur without warning and travel great distances. Deep failures would remove a large bulk of material which could cause unloading and depressurisation of the underlying magmatic system, which in turn could result in an explosive eruption and renewed volcanic activity at the Complex. The residents of Lillooet River Valley are at a greater risk than is acceptable and this needs to be recognised in order to reduce risk to as low as reasonably 
possible. Evacuation plans need to account for events of this scale and be considered in planning. 


\section{References}

Bovis M. J. (1982). 'Uphill-facing (antislope) scarps in the Coast Mountains, southwest British Columbia.' Geological Society of America Bulletin, 93, 804-812

Bovis M. J. (1990). 'Rock-slope deformation at Affliction Creek, southern Coast Mountain, British Columbia'. Canadian Journal of Earth Sciences 27, 243-254

Bovis M. J. and Evans S. G. (1996). 'Extensive deformations of rock slopes in southern Coast Mountains, southwest British Columbia, Canada'. Engineering Geology 44, 163-182

Bovis M. J. and Jakob M. (2000). 'The July 29, 1998, debris flow and landslide dam at Capricorn Creek, Mount Meager Volcanic Complex, southern Coast Mountains, British Columbia'. Canadian Journal of Earth Sciences. 37, 1321-1334

Clague J. J. (2013). 'Cryospheric hazards'. Geology Today 29 (2), 73- 79

Friele P.A. and Clague J.J. (2004). 'Large Holocene landslides from Pylon Peak, southwestern British Columbia'. Canadian Journal of Earth Sciences. 41: 165-182

Friele P., Jakob M., and Clague J. (2008). 'Hazard and risk from large landslides from Mount Meager volcano, British Columbia, Canada'. Georisk, 2 (1), 48-64

Geertsema M., Clague J. J., Schwab J. W., and Evans S. G. (2006). 'An overview of recent large catastrophic landslide in northern British Columbia, Canada'. Engineering Geology 83, 120-143

Geertsema M., Schwab J. W., Jordan P., Millard T. H., and Rollerson T. P. (2010). 'Hillslope processes'. In R. G. Pike, T. E. Redding, R. D. Moore, R. D. Winkler, and K. D. Bladon (Eds.), Compendium of Forest Hydrology and Geomorphology in British Columbia, (213-273). Province of British Columbia.

Guthrie R. H., Friele P., Allstadt K., Roberts N., Evans S. G., Delaney K. B., Roche D., Clague J. J., and Jakob M. (2012). 'The 6 August 2010 Mount Meager rock slide-debris flow, Coast Mountains, British Columbia: characteristics, dynamics, and implications for hazard and risk assessment'. Natural Hazards and Earth System Science 12, 1277-1294

Geo-community (2011) Retrieved from: www.geocomm.com

Government of Canada (2012) Environment Canada. Retrieved from: http://www.ec.gc.ca/adsccmda/default.asp?lang=en\&n=30EDCA67-1

Hewitt K., Clague J. J., and Orwin J. F (2008). 'Legacies of catastrophic rock slope failures in mountain landscapes'. Earth Science Reviews 87, 1-38

Hickson C. J., Russell J. K., and Stasiuk M. V. (1999). 'Volcanology of the 2350 B.P. Eruption of Mount Meager Volcanic Complex, British Columbia, Canada: implications for Hazards from Eruptions in Topographically Complex Terrain'. Bulletin of Volcanology 60, 489-507 Hoek E. (2007) Practical Rock Engineering. Retrieved from: http://www.rocscience.com/hoek/corner/practical rock engineering.pdf 
Holm K., Bovis M. and Jakob M. (2004). 'The landslide response of alpine basins to post-Little Ice Age glacial thinning and retreat in southwestern British Columbia'. Geomorphology 57, 201-216

Huggel C., Clague J. J., and Korup O. (2012). 'Is climate change responsible for changing landslide activity in high mountains?' Earth Surface Processes and Landforms 37, 77-91

Hungr O., Salgado F. M. and Byrne P. M. (1989). 'Evaluation of a three-dimensional method of slope stability analysis'. Canadian Geotechnical Journal 26, 679-686

Hurwitz S., Kipp K. L., Ingebritsen S. E., and Reid M. E. (2003). 'Groundwater flow, heat transport, and water table position within volcanic edifices: Implications for volcanic processes in the Cascade Range'. Journal of Geophysical Research 108(B12), 2557

Hydraulic conductivity (2013) Retrieved from: http://web.ead.anl.gov/resrad/datacoll/conuct.htm

Jakob M. and Lambert S. (2009). 'Climate change effects on landslides along the southwest coast of British Columbia'. Geomorphology 107, 275-284

Jamieson G. R. and Freeze R. A. (1983). 'Determining Hydraulic Conductivity Distributions in a Mountainous Area using Mathematical Modeling'. Ground Water 21 (2)

Jordan R. P. (1994). 'Debris flows in the southern Coast Mountains, British Columbia: dynamic behaviour and physical properties'. The University of British Columbia. PhD thesis.

Mokievsky-Zubok O. (1977). 'Glacier-caused slide near Pylon Peak, British Columbia'. Canadian Journal of Earth Sciences 14, 2657-2662

Petrakov D. A., Chernomorets S. S., Evans S. G., and Tutubalina O. V. (2008). 'Catastrophic glacial multi- phase mass movements: a special type of glacial hazard'. Advances in Geosciences 14, 211-218

Read P. B. (1990). 'Mount Meager Complex, Garibaldi Belt, Southwestern British Columbia'. Geoscience Canada, vol. 17, number 3

Rocscience (2010) Introducing Slide 6.0. Retrieved from:

http://www.rocscience.com/library/rocnews/summer2010/Introducing-Slide-6.pdf

Schilling S. P. (1998). 'LAHARZ: GIS programs for automated mapping of lahar-inundation hazard zones'. US Department of the Interior \& US Geological Survey, Open-file report, Vancouver, Washington.

Simpson K.A, Stasiuk M., Shimamura K., Clague J.J., and Friele P. (2006). 'Evidence for catastrophic debris flows in Pemberton Valley, British Columbia'. Canadian Journal of Earth Sciences 43: 679-689

Stewart M. L., Russell J. K., and Hickson C. J. (2003). 'Discrimination of hot versus cold avalanche deposits: Implications for hazard assessment at Mount Meager, B.C.'. Natural Hazards and Earth Science Systems 3: 713-724

U.S. Geological Survey, U.S. Department of the Interior (2011) Earth Explorer. Retrieved from: earthexplorer.usgs.gov 
van Wyk de Vries B. and Matela R. (1998). 'Styles of volcano-induced deformation: numerical models of substratum flexure, spreading and extrusion'. Journal of Volcanology and Geothermal Research 81, 118.

Winter T. C. (2001). 'The concept of hydrologic landscapes'. Journal of the American Water Resources Association 37 (2), 335-349 


\section{Appendix}

12.1 License and Copyright Agreement for Guthrie et al., (2012). Figures 1, 5, 6, 7 and Table 1.

The following License and Copyright Agreement is valid for any article published by Copernicus Publications on behalf of the European Geosciences Union (EGU) in the journal Natural Hazards and Earth System Sciences and its discussion forum Natural Hazards and Earth System Sciences Discussions whose original manuscript was received from 10 December 2007 on. The License and Copyright Agreement for articles based on manuscripts received before 10 December 2007 can be found here.

\section{Author's Certification}

In submitting the manuscript, the authors certify that:

- They are authorized by their co-authors to enter into these arrangements.

- The work described has not been published before (except in the form of an abstract or proceedings-type publication - including discussion papers - or as part of a published lecture or thesis), that it is not under consideration for publication elsewhere, that its publication has been approved by all the author(s) and by the responsible authorities - tacitly or explicitly - of the institutes where the work has been carried out.

- They secure the right to reproduce any material that has already been published or copyrighted elsewhere.

- They agree to the following license and copyright agreement:

\section{Copyright}

- Copyright on any article is retained by the author(s). Regarding copyright transfers please see below.

- Authors grant Copernicus Publications a license to publish the article and identify itself as the original publisher.

- Authors grant Copernicus Publications commercial rights to produce hardcopy volumes of the journal for sale to libraries and individuals.

- Authors grant any third party the right to use the article freely as long as its original authors and citation details are identified.

- The article and any associated published material is distributed under the Creative Commons Attribution $3.0 \quad$ License:

\section{Creative Commons Attribution 3.0 License}

Anyone is free:

to Share - to copy, distribute and transmit the work 
to Remix - to adapt the work

Under the following conditions:

(i) Attribution. The original authors must be given credit.

- For any reuse or distribution, it must be made clear to others what the license terms of this work are.

- Any of these conditions can be waived if the copyright holders give permission.

- Nothing in this license impairs or restricts the author's moral rights.

The full legal code $\quad$ of this license.

\section{Copyright Transfers}

Many authors have strict regulations in their contract of employment regarding their works. A transfer of copyright to the institution or company is usual as well as the reservation of specific usage rights. Please note that in case of Open Access publications in combination with a Creative Commons License a transfer of the copyright to the institution is possible as it belongs to the author anyway and is not subject to the publisher.

Any usage rights are regulated through the Creative Commons License. As Copernicus Publications is using the Creative Commons Attribution 3.0 License, anyone (the author, his/her institution/company, the publisher, as well as the public) is free to copy, distribute, transmit, and adapt the work as long as the original author is given credit (see above). Therefore, specific usage rights cannot be reserved by the author or his/her institution/company, and the publisher cannot include a statement "all rights reserved" in any published paper.

A copyright transfer from the author to his/her institution/company will be expressed in a special "Copyright Statement" at the end of the publication rather than on the first page in the article citation header. Authors are asked to include the following sentence: "The author's copyright for this publication is transferred to institution/company".

\section{Crown Copyright}

The license and copyright agreement of Copernicus Publications respects the Crown copyright. For works written by authors affiliated with the British 
Government and its institutions, a copyright statement will be included at the end of the publication. Authors are asked to use the following statement, which has been approved by the Information Policy department of The National Archives:

The works published in this journal are distributed under the Creative Commons Attribution 3.0 License. This license does not affect the Crown copyright work, which is re-usable under the Open Government Licence (OGL). The Creative Commons Attribution 3.0 License and the OGL are interoperable and do not conflict with, reduce or limit each other.

(C) Crown copyright YEAR

\section{Reproduction Request}

All articles published by Copernicus Publications are licensed under the Creative Commons Attribution 3.0 License (see details above) together with an author copyright. Therefore, there is no need from the publisher's side to allow/confirm a reproduction. We would suggest contacting the author to inform him/her about the further usage of the material. But as the author decided to publish the scientific results under the "CC- BY" license, he/she decided to share the work under the condition that the original authors must be given credit.

Available from:

http://www.natural-hazards-and-earth-system-

sciences.net/general_information/license_and_copyright.html 


\subsection{License for Bovis \& Jakob (2000). Figures 3 and 19.}

Dear Miss. Rachel Hetherington,

Thank you for placing your order through Copyright Clearance Center's RightsLink service. NRC Research Press has partnered with RightsLink to license its content. This notice is a confirmation that your order was successful.

Your order details and publisher terms and conditions are available by clicking the link below:

http://s100.copyright.com/CustomerAdmin/PLF.jsp?ref=50d9e00f-552b-4080-91fc6252e38b776d

\section{Order Details}

Licensee: Rachel Hetherington License Date: Jul 15, 2013

License Number: 3190190592386

Publication: Canadian Journal of Earth Sciences

Title: The July 29, 1998, debris flow and landslide dam at Capricorn Creek, Mount Meager Volcanic Complex, southern Coast Mountains, British Columbia

Type of Use: Thesis/Dissertation Total: 0.00 USD

Please note: Online payments are charged immediately after order confirmation; invoices are issued daily and are payable immediately upon receipt. 


\subsection{License for Friele \& Clague (2004). Figure 18.}

Dear Miss. Rachel Hetherington,

Thank you for placing your order through Copyright Clearance Center's RightsLink service. NRC Research Press has partnered with RightsLink to license its content. This notice is a confirmation that your order was successful.

Your order details and publisher terms and conditions are available by clicking the link below:

http://s100.copyright.com/CustomerAdmin/PLF.jsp?ref=e35bc168-7e04-4c66-894a-

\section{7cbba321}

\section{Order Details}

Licensee: Rachel Hetherington

License Date: Jul 15, 2013

License Number: 3190190877534

Publication: Canadian Journal of Earth Sciences

Title: Large Holocene landslides from Pylon Peak, southwestern British Columbia Type of Use: Thesis/Dissertation

Total: 0.00 USD

Please note: Online payments are charged immediately after order confirmation; invoices are issued daily and are payable immediately upon receipt. 


\subsection{License for Hewitt et al., (2008). Figure 11.}

Dear Miss. Rachel Hetherington,

Thank you for placing your order through Copyright Clearance Center's RightsLink service. Elsevier has partnered with RightsLink to license its content. This notice is a confirmation that your order was successful.

Your order details and publisher terms and conditions are available by clicking the link below:

http://s100.copyright.com/CustomerAdmin/PLF.jsp?ref=7616aaf6-2ec9-4818-ae0a$\underline{\mathrm{eb} 2 \mathrm{f} 2 \mathrm{c} 01 \mathrm{~d} 801}$

\section{Order Details}

Licensee: Rachel Hetherington

License Date: Jul 15, 2013

License Number: 3190200065545 Publication: Earth-Science Reviews

Title: Legacies of catastrophic rock slope failures in mountain landscapes Type of Use: reuse in a thesis/dissertation

Total: 0.00 USD

Please note: Online payments are charged immediately after order confirmation; invoices are issued daily and are payable immediately upon receipt. 


\subsection{License for Holm et al., (2004). Figure 12.}

Dear Miss. Rachel Hetherington,

Thank you for placing your order through Copyright Clearance Center's RightsLink service. Elsevier has partnered with RightsLink to license its content. This notice is a confirmation that your order was successful.

Your order details and publisher terms and conditions are available by clicking the link below:

http://s100.copyright.com/CustomerAdmin/PLF.jsp?ref=c6d9e5a2-f49e-42b1-b20f-

$\underline{442 \mathrm{~d} 9 \mathrm{ea} 11 \mathrm{e} 97}$

\section{Order Details}

Licensee: Rachel Hetherington License Date: Jul 15, 2013

License Number: 3190200207231 Publication: Geomorphology

Title: The landslide response of alpine basins to post-Little Ice Age glacial thinning and retreat in southwestern British Columbia

Type of Use: reuse in a thesis/dissertation Total: 0.00 USD

Please note: Online payments are charged immediately after order confirmation; invoices are issued daily and are payable immediately upon receipt. 


\subsection{Copyright Agreement for Read (1990). Figures 4 and 8.}

GAC ${ }^{\circledR 1}$ s Fair Dealing/Fair Use policy, published online at http://www.gac.ca, states:

"Permission to use a single figure or table from any one manuscript published by GAC (including those appearing in a Special Paper, Short Course Notes volume, GeoText, Geolog issue, Geoscience Canada issue and Geoscience Canada Reprint Series volume, and - through agreement with their publishers - Paleontographica Canadiana and Paleontology Division publications) is considered 'fair dealing' under the Canadian Copyright Act and 'fair use' by GAC, and no other permission need be granted, subject to the image being appropriately cited in all reproductions. The same fair dealing/fair use policy applies to sections of text up to 100 words in length.

"Publishers requiring written permission should be advised that charges may apply."

Please note that for the purposes of applying the above to non-commercial re-use, we consider two images to fall within these guidelines.

Please advise if further permission is required. 


\subsection{License for Simpson et al., (2006). Figures 2 and 9.}

Dear Miss. Rachel Hetherington,

Thank you for placing your order through Copyright Clearance Center's RightsLink service. NRC Research Press has partnered with RightsLink to license its content. This notice is a confirmation that your order was successful.

Your order details and publisher terms and conditions are available by clicking the link below:

http://s100.copyright.com/CustomerAdmin/PLF.jsp?ref=04b58743-9ea9-4fa9-8a82$\underline{1 \mathrm{~d} 6 \mathrm{edcf} 757 \mathrm{ff}}$

\section{Order Details}

Licensee: Rachel Hetherington

License Date: Jul 15, 2013

License Number: 3190181469596

Publication: Canadian Journal of Earth Sciences

Title: Evidence for catastrophic volcanic debris flows in Pemberton Valley, British Columbia

Type of Use: Thesis/Dissertation

Total: $0.00 \mathrm{GBP}$

Please note: Online payments are charged immediately after order confirmation; invoices are issued daily and are payable immediately upon receipt. 


\subsection{License for Google Earth. Figures 10, 13, 14, 15, 16 and 17.}

\section{Use of images}

This article explains that:

You can use Google Earth imagery for personal use, but cannot sell it to others. We're flattered to hear that you're further incorporating Google Earth into your online world. You can personally use an image from the application (for example on your website, on a blog or in a word document) as long as you preserve the copyrights and attributions including the Google logo attribution. However, you cannot sell these to others, provide them as part of a service, or use them in a commercial product such as a book or TV show without first getting a rights clearance from Google. https://support.google.com/earth/answer/21422?hl=en

To determine if your proposed use of Content is acceptable, you should first read closely the applicable Terms of Service:

- Google Maps/Google Earth Terms and Conditions

- Google Maps/Google Earth APIs Terms of Service

Your use of Content, as defined in the Terms of Service, in anything from marketing and promotional materials to films and books is first and foremost governed by the license provided in the applicable Terms of Service for the product. In certain circumstances, Google may be able to grant you a broader license to use the Content in a manner not covered in the Terms of Service. Plus, apart from any license granted to you by Google, your use of Content may be acceptable under principles of "fair use."

Fair use is a concept under copyright law in the U.S. that, generally speaking, permits you to use a copyrighted work in certain ways without obtaining a license from the copyright holder. There are a variety of factors that affect whether your use of Content would be considered fair use, including the purpose and character of your use, the nature of the copyrighted work, the amount of the copyrighted material used, and the effect of your use upon the potential market for the copyrighted work. For example, there are differences between use in a for-fee service and use in a work of scholarship, or the use of a single map screenshot and the use of detailed map images for an entire country. There are similar, although generally more limited, concepts in other countries' copyright laws, including a concept known as "fair dealing" in a number of countries. That all being said...

Please do not request that we interpret whether your use of Content is fair use. Google cannot tell you if your use of Content from our products would be fair use or would be considered fair dealing; these are legal analyses that depend on all of the specific facts of your proposed use. We suggest you speak with an attorney if you have questions regarding fair use of copyrighted works.

No explicit permission is required for your print project. We are unable to sign any letter or contract specifying that your project has our explicit permission. 
No explicit permission is required for your project. We are unable to sign any letter or contract specifying that your project has our explicit permission.

http://www.google.com/permissions/geoguidelines.html 


\subsection{License agreement from USGS. Figure 30.}

Most U.S. Geological Survey (USGS) information resides in the public domain and may be used without restriction. When using information from USGS information products, publications, or Web sites, we ask that proper credit be given. Acknowledging or crediting the USGS as an information source can be provided by including a line of text citation such as those shown below. Note that some non USGS photographs, images, and/or graphics are used by the USGS with permission from the copyright holder. To use these copyrighted materials, you must obtain permission from the copyright holder under the copyright law. 